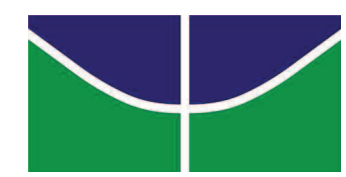

Universidade de Brasília (UnB)

Faculdade de Economia, Administração, Contabilidade e Ciência da Informação e Documentação (FACE)

Programa de Pós-Graduação em Administração (PPGA)

JANSEN ROGER SOUSA RODRIGUES

AVALIAÇÃO DO IMPACTO DE UMA TECNOLOGIA DA INFORMAÇÃO PARA GERENCIAMENTO DE SERVIÇOS DE SAÚDE NA PERCEPÇÃO DOS CLIENTES INTERNOS DO HOSPITAL UNIVERSITÁRIO DE BRASÍLIA 


\section{AVALIAÇÃO DO IMPACTO DE UMA TECNOLOGIA DA INFORMAÇÃO PARA GERENCIAMENTO DE SERVIÇOS DE SAÚDE NA PERCEPÇÃO DOS CLIENTES INTERNOS DO HOSPITAL UNIVERSITÁRIO DE BRASÍLIA}

Monografia apresentada à Faculdade de Economia, Administração, Contabilidade e Ciência da Informação e Documentação (FACE), da Universidade de Brasília, como requisito parcial à obtenção do grau de Especialista em Gestão Universitária.

Orientadora: Profa Dra. Maria de Fátima Bruno de Faria 
AVALIAÇÃO DO IMPACTO DE UMA TECNOLOGIA DA INFORMAÇÃO PARA GERENCIAMENTO DE SERVIÇOS DE SAÚDE NA PERCEPÇÃO DOS CLIENTES INTERNOS DO HOSPITAL UNIVERSITÁRIO DE BRASÍLIA

Monografia apresentada à Faculdade de Economia, Administração, Contabilidade e Ciência da Informação e Documentação (FACE), da Universidade de Brasília, como requisito parcial à obtenção do grau de Especialista em Gestão Universitária.

Data de aprovação

Profa $^{a}$ Dra. Maria de Fátima Bruno de Faria Orientadora

Prof $^{\circ}$ Dr. César Augusto Tibúrcio Silva Membro da Banca Examinadora 
A todas as pessoas que acreditaram no meu sucesso, especialmente minha mãe Denilce. 


\section{AGRADECIMENTOS}

A orientação cuidadosa e a atenção da Professora Fátima Bruno.

Aos colaboradores do Hospital Universitário de Brasília, que de forma cordial me ajudaram no decorrer da pesquisa.

A todos os colaboradores do PPGA e da FACE.

Aos professores do Curso de Especialização especialmente ao professor César Augusto Tibúrcio Silva pelo empenho na realização do curso e pela dedicação dispensada a todos os alunos.

E, finalmente, agradeço a todos os colegas e amigos do curso com quem passei momentos inesquecíveis e que de alguma forma contribuíram para o sucesso desta conquista. 


\section{RESUMO}

A tecnologia da informação ( $\mathrm{Tl}$ ) pode ser considerada a mais recente e influente das tecnologias inseridas na sociedade, trazendo consigo uma série de impactos bem como a necessidade de pesquisas para o melhor entendimento desse novo fenômeno. O presente estudo teve como objetivo avaliar o impacto de uma tecnologia da informação para gerenciamento de serviços de saúde na percepção dos colaboradores do HUB. Foi realizada revisão teórica, a fim de identificar as dimensões relativas ao impacto da $\mathrm{TI}$ no trabalho na literatura acadêmica para o melhor entendimento da pesquisa em sua totalidade. $O$ método de investigação utilizado foi o quantitativo através do levantamento de dados (survey). Foram selecionados 75 colaboradores da instituição para responder o questionário. O critério para escolha dessa amostra foi que os respondentes teriam que utilizar o sistema há, no mínimo, um ano. $O$ instrumento foi composto por perguntas fechadas, em linguagem apropriada aos participantes e estruturadas em uma escala tipo Likert, variando de 1 a 5 pontos itens de caracterização dos participantes e um campo para os participantes exporem livremente informações que julgassem relevantes. Para tanto, foi utilizada a escala denominada Avaliação do Impacto da TI no Trabalho que foi elaborada e validada por Lucht, Hoppen e Maçada (2007). A pesquisa alcançou resultados que mostraram a necessidade de uma maior integração entre os usuários e os setores de desenvolvimento do sistema e ajustes nas políticas de TI do órgão estudado, especialmente no tocante aos fatores Inovação, Satisfação do Usuário e Decisão.

Palavras Chave: Tecnologia de Informação, Impacto de TI, Gestão Hospitalar. 


\section{LISTA DE ABREVIATURAS}

FUB Fundação Universidade de Brasília

GSWEB Gerenciador de Informações da Saúde de Individual

HDFPM Hospital do Distrito Federal Presidente Médici

HUB Hospital Universitário de Brasília

HSU Hospital dos Servidores da União

IPASE Instituto de Pensão e Aposentadoria dos Servidores do Estado

MEC Ministério da Educação

TI Tecnologia da Informação

SI Sistemas de Informação

SIG Sistemas de Informações Gerenciais

$\mathrm{SIH} \quad$ Sistemas de Informações Hospitalares

SUS Sistema Único de Saúde

UnB Universidade de Brasília 


\section{LISTA DE FIGURAS}

Figura 1 - Atividades dos Sistemas de Informação …………………………….........15

Figura 2 - Um SI: não apenas um computador ............................................................ 17

\section{LISTA DE GRÁFICOS}

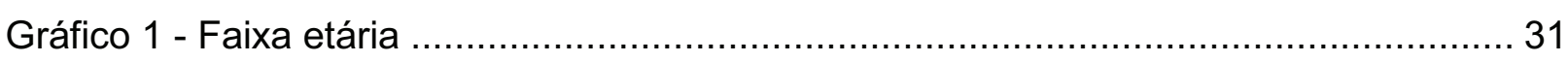

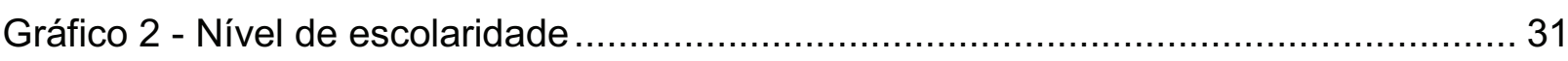

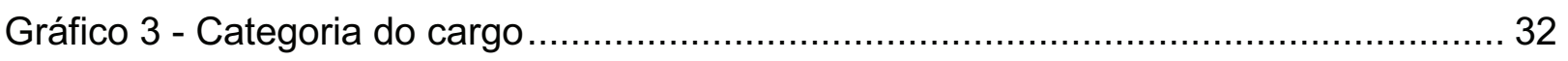

\section{LISTA DE QUADROS}

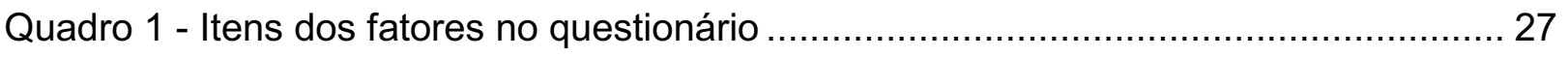

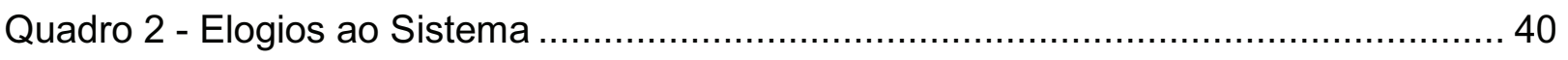

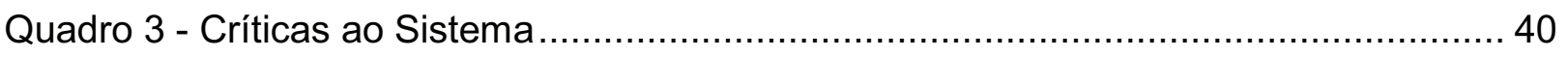




\section{LISTA DE TABELAS}

Tabela 1 - Média e desvio padrão dos fatores. 32

Tabela 2 - Estatística descritiva dos itens que compõe o fator Segurança da Informação.33

Tabela 3 - Estatística descritiva dos itens que compõe o fator Controle Gerencial. 34

Tabela 4 - Estatística descritiva dos itens que compõe o fator Qualidade da Informação. 35

Tabela 5 - Estatística descritiva dos itens que compõe o fator Produtividade 36

Tabela 6 - Estatística descritiva dos itens que compõe o fator Decisão. 37

Tabela 7 - Estatística descritiva dos itens que compõe o fator Satisfação do Usuário...... 38

Tabela 8 - Estatística descritiva dos itens que compõe o fator Inovação ........................ 38

Tabela 9 - Correlações Significativas com os fatores e as variáveis independentes 39 


\section{SUMÁRIO}

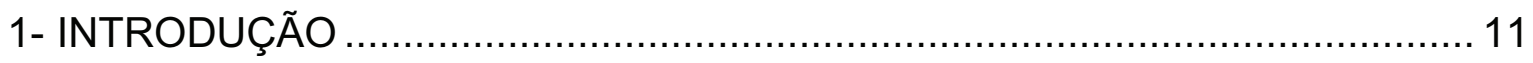

1.1 - Formulação do Problema ............................................................... 12

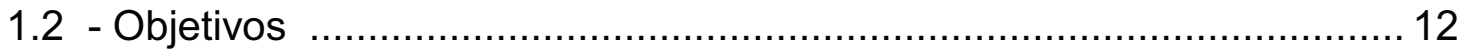

1.2 .1 - Objetivo Geral...................................................... 12

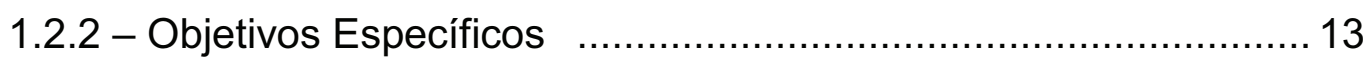

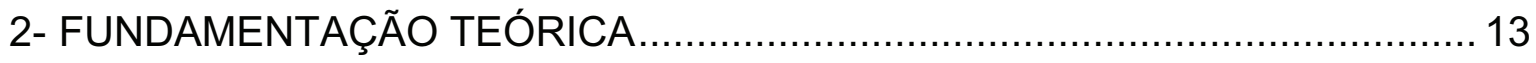

2.1 - Gestão de Serviços Hospitalares na Rede Pública ......................... 13

2.2 - Conceitos e componentes da Tecnologia da Informação (TI).............. 14

2.3 - Sistemas de Informação .......................................................... 16

2.3.1 - Sistemas de Informação Hospitalar (SIH) .............................. 18

2.4 - Impacto da TI no Trabalho .................................................. 19

2.4.1 - Qualidade da Informação ............................................. 19

2.4 .2 - Impacto da TI sobre a Inovação ..................................... 20

2.4.3 - Impacto da TI sobre a Produtividade.................................. 21

2.4.4 - Impacto da TI sobre o Controle Gerencial................................ 21

2.4.5 - Impacto da TI sobre a Satisfação dos Usuários ........................ 22

2.4.6 - Impacto da TI sobre o Processo Decisório .............................. 23

2.4.7 - Impacto da TI sobre a Segurança da Informação ..................... 24

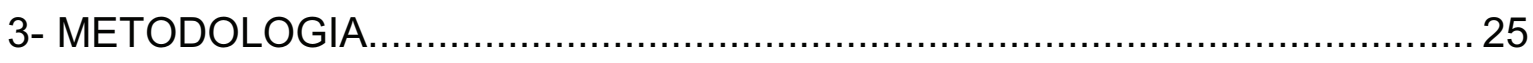

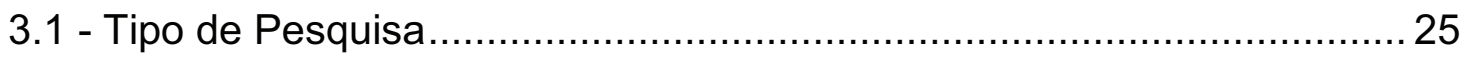

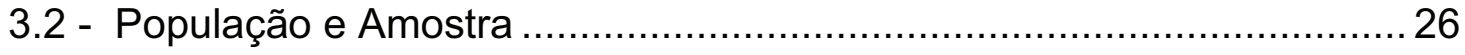

3.3 - Instrumento de Coleta de Dados ................................................... 26

3.4 - Procedimento de Coleta dos Dados ............................................ 28

3.5 - Analise dos Dados............................................................ 28

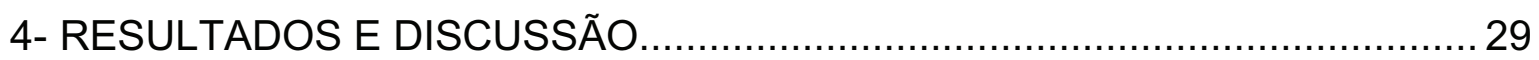


4.1 - Caracterização da Instituição do Sistema GSWEB e dos Participantes da Pesquisa. 29

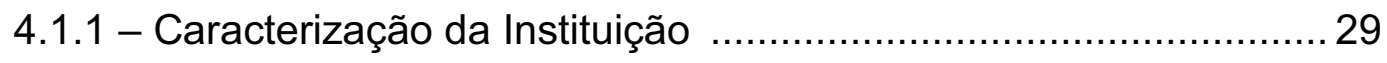

4.1.2 - Caracterização do Sistema GSWEB ……………………....... 30

4.1.3 - Caracterização dos Participantes da Pesquisa ............................ 30

4.2 - Resultado das médias e desvios padrão dos fatores da escala de Avaliação de Impacto de TI no Trabalho 32

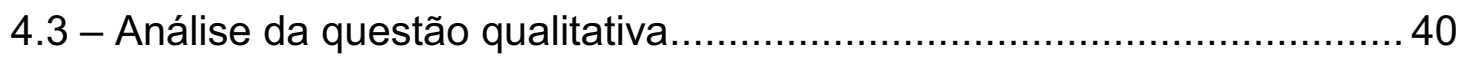

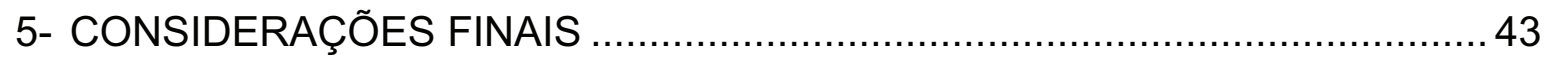

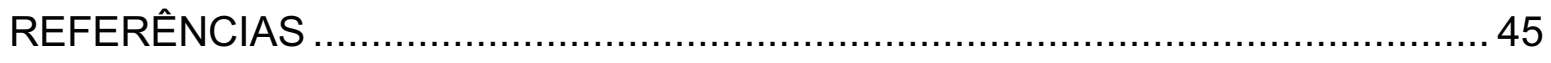

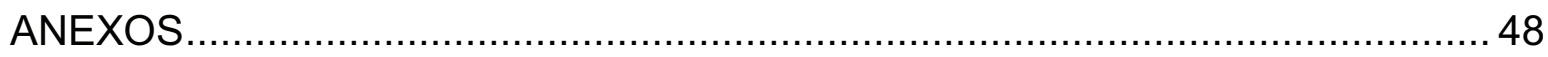




\section{INTRODUÇÃO}

As últimas décadas do século $X X$ foram marcadas por rápidas e vertiginosas mudanças tecnológicas, econômicas e sociais que transformaram o mundo do trabalho, das empresas e, conseqüentemente, das pessoas. Essa época foi marcada por uma epidemia de projeções e previsões sobre os futuros acontecimentos do século $\mathrm{XXI}$, onde a gestão das empresas foi fundamental na reformulação do ambiente dos negócios, das novas configurações organizacionais e do perfil do gestor frente a essas transformações (RUAS, 2000).

Pressionadas por melhorias, as organizações buscam modelos de gestão mais eficazes que resultem na melhoria da qualidade dos produtos e dos serviços oferecidos aos clientes que estão cada vez mais exigentes e conscientes dos seus direitos.

Nas organizações públicas, sobretudo nas organizações hospitalares, por uma questão de adaptação a esse momento de transformação, ocorreram mudanças significativas nas formas de trabalho, onde foram abolidas tradicionais $e$ conservadoras práticas até então implementadas para dar lugar a novas e modernas tecnologias e estruturas organizacionais, criadas para adequar a organização e os profissionais aos ambientes turbulentos como os dos dias atuais.

A Tecnologia da Informação (TI) é parte integrante desse processo de transformação, tornando necessário o investimento em novas tecnologias, na implementação de novos processos organizacionais e em continuas adaptações na postura estratégica das organizações (BRITO; ANTONIALLI; SANTOS, 1997).

Deste modo, conforme Perottoni et al. (2001, p.1), "as organizações devem investir em equipamentos que possam suprir suas necessidades, em softwares que dão suporte às atividades desempenhadas pelos seus profissionais, assim como no aprimoramento de seus colaboradores".

Para adequar-se a esse novo paradigma, a gestão de organizações hospitalares evoluiu para um processo mais complexo de análises gerenciais, com o objetivo de pensar estrategicamente frente aos novos desafios desenvolvendo competências técnicas e gerenciais modernas que permitam identificar e apresentar soluções junto aos problemas que permeiam a área de saúde. 
Ao considerar que o impacto de uma Tl é de suma importância, pois provoca alterações, nos padrões de trabalho, nos valores das pessoas e das organizações, o presente trabalho tem como objetivo avaliar o impacto de uma tecnologia da informação para gerenciamento de serviços de saúde na percepção dos clientes internos do Hospital Universitário de Brasília. Essa avaliação poderá orientar as ações do hospital, no sentido de aprimorar o seu desempenho futuro.

\subsection{Formulação do Problema da Pesquisa}

Qual o impacto de uma tecnologia da informação para gerenciamento de serviços de saúde na percepção dos clientes internos do Hospital Universitário de Brasília?

\subsection{Objetivos}

\subsubsection{Objetivo Geral}

O objetivo geral do estudo é avaliar o impacto de uma tecnologia da informação para gerenciamento de serviços de saúde na percepção dos clientes internos do Hospital Universitário de Brasília.

\subsubsection{Objetivos Específicos}

- Identificar as dimensões relativas ao impacto da TI no trabalho na literatura científica.

- Descrever os resultados obtidos pela organização com a tecnologia adotada;

- Verificar a existência de divergências na percepção de impacto da TI, quando considerados diferentes grupos de trabalhadores;

- Indicar as possíveis falhas e sugerir medidas para minimizar os impactos das inserções de novas tecnologias na organização pesquisada. 


\section{FUNDAMENTAÇÃO TEÓRICA}

O presente capítulo apresenta os resultados obtidos por meio de pesquisa bibliográfica, e enfatiza conceitos acerca de gestão de serviços em saúde, tecnologias de informação, sistemas de informação, impactos da TI sobre qualidade da informação, inovação, produtividade, controle gerencial, processo decisório, satisfação dos usuários e segurança da informação. Tais conceitos tornam-se necessários para um melhor entendimento da pesquisa em sua totalidade, da formulação do problema à análise dos resultados.

\subsection{Gestão de serviços hospitalares na rede pública}

Após o reconhecimento pelo Estado brasileiro do direito universal à saúde, foi criado em 1988 o Sistema Único de Saúde (SUS), que segundo Rodrigues (2003, p.3) "é regido pela lógica do direito social, de caráter coletivo, onde o Estado atua diretamente tanto na formulação e gestão de políticas, como na gestão e provisão de ações e serviços de saúde". A lógica do sistema público de saúde corresponde, a desmercantilização do acesso aos serviços de saúde. É neste âmbito e dentro dessa lógica que atuam, os hospitais universitários.

Tomando como base essa lógica, os hospitais universitários como parte integrante dos serviços de uma universidade pública têm como preceito a manutenção da tríade, ensino, pesquisa e extensão, vinculada à assistência a comunidade e integrado com a rede SUS. Os hospitais universitários devem oferecer serviços públicos de qualidade, cumprindo seu papel de formação de profissionais para atuação na área da saúde e desenvolver pesquisas que avancem na busca de soluções para as questões da saúde.

Deste modo, a organização hospitalar é semelhante a uma empresa pelas funções administrativas apresentadas. Nos dias atuais, o hospital apresenta-se como um instrumento de intervenção terapêutica com o objetivo de alcançar a cura de doentes (GURGEL JÚNIOR; VIEIRA, 2002).

Gurgel Júnior e Vieira (2002) consideram a organização hospitalar como uma das mais complexas, pela nobreza e amplitude da sua missão, além de apresentar equipe multidisciplinar com elevado grau de autonomia, para dar assistência à saúde a 
pacientes, onde se utiliza, rotineiramente e de forma crescente, tecnologia de ponta. Além de ser um espaço de prática de ensino-aprendizagem e produção científica.

Segundo Drucker (1987 apud SILVA; SOUZA, 2003, p.4), o hospital reúne muitas atividades diferentes, "nos hospitais estão reunidos vários serviços e situações simultâneas: hospital é hotel, lavanderia, serviços médicos, limpeza, vigilância, restaurante, recursos humanos, relacionamento com o consumidor".

$\mathrm{Na}$ esfera hospitalar, a tecnologia não substitui a mão de obra humana, pelo contrário, gera a necessidade de profissionais especializados, ocasionando a diminuição dos custos da inovação e conseqüentemente o aumento o nível de especialização e profissionalização nessas instituições (SILVA; SOUZA, 2003).

Borba (1991) destaca que o gestor hospitalar deve apresentar como requisitos, a efetiva e eficiente administração para o processo de desenvolvimento da unidade de saúde. Portanto, necessita de informações e conhecimentos a respeito de suas funções, a fim de oferecer o necessário para garantir o efetivo atendimento aos beneficiários dos serviços de saúde. Cabe ao administrador hospitalar ainda, responder pela qualidade dos serviços e cuidados prestados, formação e composição do corpo clínico, adequada visão da função hospitalar e definição clara da estrutura orgânica. "O administrador eficaz não confunde o verdadeiro problema com os sintomas cujo tratamento resulta apenas num alívio temporário e não remove as causa" (BORBA, 1991, p, 25).

A próxima seção é dedicada à análise de conceitos e componentes da TI sob a percepção de diversos pesquisadores do tema, a fim de formar alicerces teóricos para embasar cientificamente a presente pesquisa.

\subsection{Conceitos e componentes da tecnologia da informação (TI)}

A crescente evolução ocorrida através do advento da informática vem influenciando, os modelos de administração e gerenciamento das organizações, e provocado mudanças significativas no comportamento das pessoas, tanto na vida profissional, quanto na vida pessoal (LAUDON; LAUDON, 1999).

Tomando por base esse novo paradigma tecnológico, neste trabalho será utilizado o conceito de tecnologia da informação que segundo Marcovitch (1996) pode ser entendido como o complexo tecnológico que envolve computadores, softwares, 
redes de comunicação eletrônica, rede digital de serviços, tecnologias de telecomunicações, protocolos de transmissão de dados e outros serviços.

Desta forma, a TI, "representa um conjunto de componentes inter-relacionados trabalhando juntos para coletar, recuperar, processar, armazenar e distribuir informação" (Figura 1), com a finalidade de facilitar o planejamento, o controle, a coordenação e o processo decisório em empresas e outras organizações (LAUDON; LAUDON, 1999, p.4).

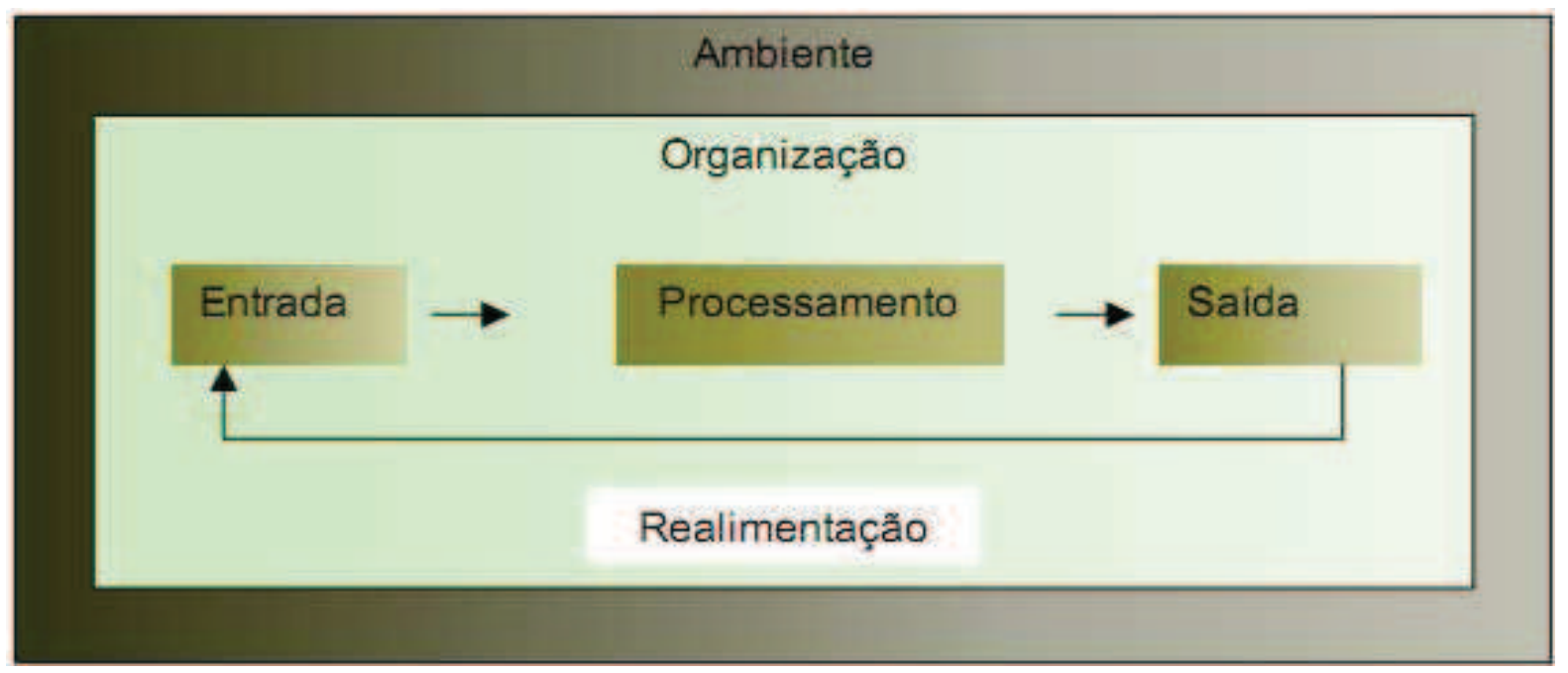

Figura 01 - Atividades dos Sistemas de Informação.

Fonte: Laudon e Laudon (1999, p.4).

A tecnologia da informação propicia os alicerces para as várias atividades vitais de uma organização, possibilitando mudanças essenciais na forma como o trabalho se processa, apresentando novas oportunidades estratégicas que reavaliam suas missões e operações, uma vez que são elas que apóiam as decisões e exercem influências sobre o comportamento das pessoas. (OLIVEIRA, 1996).

A associação entre a TI e a estratégia de uma empresa está muito clara atualmente. Dessa forma segundo Oliveira (1996) a TI tem ocupado espaço significativo no planejamento, processos e direção das empresas repercutindo em diversos aspectos da administração corporativa.

Para Brito, Antonialli e Santos (1997 p.78) um novo paradigma começa a ser delineado, marcado por diversas tendências relativas às tecnologias da informação. 
Essa nova era é caracterizada pelo crescente uso dos computadores nas organizações; pela convergência entres as mídias, computadores e redes de comunicações; automação da organização; processos de trabalho com maior agregação de valor proporcionado pela Tl; aumento da competição global e adoção de padrões tecnológicos globais. A base de transformação organizacional e da vantagem competitiva, neste cenário, será a informação traduzida em conhecimento.

Desta forma, a informação passa a ser um recurso essencial para as organizações, permitindo assim o alinhamento estratégico que gera as condições necessárias para alcançar os objetivos e cumprir a missão corporativa (BRITO; ANTONIALLI; SANTOS, 1997).

Portanto, a TI fornece as ferramentas necessárias para o desenvolvimento de um sistema de informações adequado às necessidades das organizações hospitalares. Cabe aos indivíduos envolvidos nesse processo, um comprometimento acerca desses princípios norteadores, de modo que seja possível definir as informações necessárias para que o processo de informatização organizacional envolva os usuários em todas as etapas do processo.

\subsection{Sistemas de informação (SI)}

Borges (2000) conceitua sistema como um conjunto de elementos com funções próprias que interagem e agem em conjunto para atingir um ou mais objetivos.

Segundo Perottoni et al. (2001, p. 14), os Sls podem ser entendidos a partir de três dimensões:

Humana: à medida que as pessoas interagem com os sistemas, alimentandoos com dados e, utilizando as informações resultantes nas suas atividades e integrando-os a sua rotina de trabalho; Organizacional: à medida que a cultura da empresa e o ambiente em que a mesma se insere afetam o delineamento dos sistemas de informações; Tecnológica: à medida que é preciso selecionar a tecnologia adotada para entrada, saída, processamento e armazenamento da informação.

Laudon e Laudon (1999) consideram um erro descrever os sistemas de informação apenas em temos de computador. Segundo os autores, não é possível entender ou usar um sistema de informação sem a compreensão de suas dimensões em termos de organização e de pessoas, bem como de suas dimensões técnicas. Dessa forma, Laudon e Laudon (1999, p.5) consideram que "um sistema de 
informação é parte integrante de uma organização e produto dos componentes tecnologia, organizações e pessoas" (figura 2).

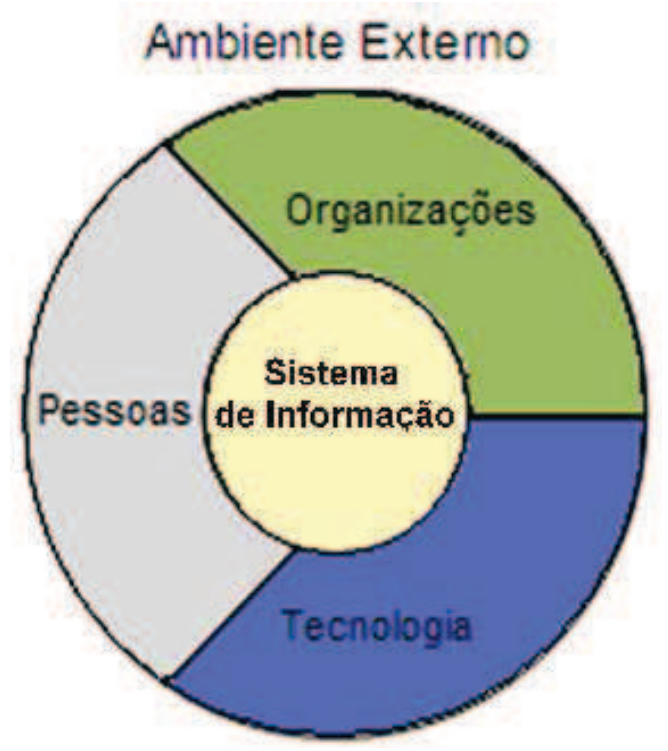

Figura 2: Um SI: não apenas um computador.

Fonte: Laudon e Laudon (1999, p.5).

Segundo Laudon e Laudon (1999) o uso de um SI vem transformando a maneira que o trabalho é conduzido, dando aos indivíduos novas ferramenta para a melhoria de suas atividades e definindo como a informação é acessada e usada para administrar os recursos de uma organização.

Stumpf e Freitas (1997) enfatizam que a informação representa dados em uso e este uso implica nos usuários, portanto, o sistema deve identificar quem, quando, onde e como a informação é necessária. Deste modo, a concepção de um SI, não pode ser conduzida, apenas, por profissionais da área de informática. Essa tarefa também requer um alto nível de envolvimento e de controle dos usuários finais.

Segundo Stumpf e Freitas (1997, p.78) o envolvimento do usuário na concepção e na operação de um SI tem várias conseqüências positivas, dentre elas:

Primeiramente, se os usuários estão envolvidos profundamente na definição dos sistemas, terão mais oportunidades para moldar esses sistemas de acordo com as suas prioridades e necessidades. Segundo estarão mais aptos a reagir positivamente ao sistema, porque tiveram participação ativa na sua definição e desenvolvimento. A sua participação na implementação favorece a aceitação em relação ao sistema e às mudanças provocadas por este. 


\subsubsection{Sistemas de Informação Hospitalar (SIH)}

O uso de computadores e de redes de computadores nos serviços de saúde tem adquirido grande relevância na administração das informações em saúde. Exatamente por isso que os computadores e os sistemas de informação que viabilizam seu funcionamento tornam-se vitais dentro das organizações.

Segundo Stumpf e Freitas (1997), os sistemas de informação destinados aos serviços de saúde começaram a ser usados em meados da década de 50, para funções administrativas e métodos estatísticos e financeiros dos hospitais. Com o advento dos microcomputadores foi permitido aos envolvidos nesses serviços, o acesso a bases de dados dos hospitais possibilitando a interligação e a comunicação entre praticamente todas as funções.

Para Stumpf e Freitas (1997), cabe as pessoas envolvidas no processo de implantação de um sistema de informações hospitalares, ter um comprometimento no sentido de envolver os usuários do sistema em todas as etapas do processo informatização, a fim de garantir o atendimento da missão institucional da organização no seu objetivo de prestar assistência de alta qualidade.

Segundo Sabbatini (1993), nos dias atuais é cada vez mais difícil à operação de um hospital sem o uso da tecnologia da informação. O hospital é uma organização complexa e possui uma quantidade imensa de informações que precisam ser armazenadas, processadas, gerenciadas e distribuídas.

Entretanto Sabbatini (1993, p.5) salienta que,

A informatização de um hospital não é uma tarefa fácil, principalmente quando o seu objetivo principal é integrar, através de computadores, todos os aspectos referentes às suas atividades-meio e às atividades-fim. Um dos aspectos fundamentais para o sucesso dessa operação, é o estabelecimento de uma estrutura gerencial e operacional adequada o Centro de Informática Hospitalar, idealizado de modo a se adequar ao organograma já existente no hospital, mas, ao mesmo tempo, buscando modernizá-lo com o objetivo de integrar a Informática da maneira a mais completa e eficiente possível.

Dessa forma, infere-se que os SIHs tem como principal objetivo integrar por meio de recursos tecnológicos, todos os aspectos referentes às atividades hospitalares, entretanto apresenta um processo complexo na fase de implantação. 
A próxima seção é dedicada à análise de impacto da TI sobre as organizações e apresenta a relação dessas tecnologias com os temas qualidade da informação, inovação, produtividade, controle gerencial, satisfação do usuário, processo decisório e segurança da informação.

\subsection{Impacto da TI no trabalho}

Segundo Lucht, Hoppen e Maçada (2007) o impacto da TI assume diferentes significados, dependendo do enfoque que se deseja avaliar. Os efeitos sentidos na implantação de uma nova tecnologia no ambiente de uma organização pública podem ser vislumbrados, por exemplo, sob os aspectos da organização, dos processos de trabalho ou até mesmo do indivíduo.

A seguir, são abordadas as bases conceituais a respeito modelos de avaliação do impacto da Tl e do impacto da TI na percepção de valor dos usuários quanto ao trabalho.

\subsubsection{Impacto da TI sobre a Qualidade da informação}

A qualidade da informação é uma condição básica e no cenário organizacional nos dias atuais. Sendo, portanto, fundamental para o aumento da qualidade dos processos de tomada de decisões de um grupamento gerencial.

Almeida e Varvakis (2005) afirmam que o valor da informação depende de qualidades intrínsecas e extrínsecas e conceituam valor da informação como a validade e relevância que a informação representa a um determinado indivíduo ou grupo.

Os atributos da qualidade da informação associada ao usuário segundo Oleto (2006, p.60), "são adequação da indexação e classificação (atributo do sistema), eficácia, eficiência da recuperação (atributo do sistema), impacto, relevância, utilidade, valor esperado, valor percebido e valor de uso".

A análise da qualidade da informação associada como um produto, enfatiza a informação como coisa, atribuindo à qualidade da informação algumas dimensões, tais como abrangência, acessibilidade, atualidade, confiabilidade, objetividade, precisão e validade. (OLETO, 2006). 
Portanto, verifica-se que os usuários percebem o valor da qualidade da informação ligado a atributos como a relevância, a utilidade, a acessibilidade, velocidade, facilidade de uso do sistema e velocidade de obtenção.

$O$ instrumento utilizado nesta pesquisa visa mensurar a qualidade das informações de uma $\mathrm{Tl}$, através de questões que buscam identificar, de acordo com a percepção dos usuários se as informações geradas são de fácil compreensão, de fácil acesso, fáceis de se obter, se podem ser recuperadas com facilidade e se podem ser recuperadas rapidamente.

\subsubsection{Impacto da TI sobre a Inovação}

A capacidade de inovação é essencial para a sobrevivência das organizações. Assim, a capacidade de percepção, criação e disseminação de novas tecnologias e métodos de trabalho encontram cada vez mais espaços nas organizações atuais.

Conforme Schumpeter (1982 apud FREITAS; CAMPOS; CAMPOS, 2006) a inovação relaciona-se com a criação de produtos, serviço ou processo que seja novo, embora esteja geralmente associada a importantes avanços em produtos ou processos, a maior parte das inovações são baseadas no efeito de mudanças ou na combinação criativa de técnicas, idéias ou métodos existentes.

A inovação pode ser percebida em diversos campos como: nas relações de produção de bens e serviços; nas relações de trabalho; nas relações de comunicação; na transmissão de conhecimentos, no desenvolvimento de novas tecnologias. Schmitz e Forcellini (2007) destacam que a inovação deve ser uma das funções básicas da organização, pode ser considerada inovadora.

\footnotetext{
Para tanto, os administradores devem praticar a inovação de forma sistemática, tendo sempre um processo organizado que sustente e acompanhe a inovação desde o planejamento até o seu lançamento e acompanhamento no mercado. A inovação estará consolidada se agregar, de maneira ampla, valor às ações da empresa, influenciando a economia como um todo (SCHMITZ; FORCELLINI, 2007, p. 4).
}

Segundo Tidd, Bessant e Pavitt (2008), a gestão da inovação corresponde a atividades gerenciais e técnicas voltadas para a implantação bem sucedida de novas idéias e práticas, sob a forma de novos produtos e processos, cuja utilização pode acarretar vantagens competitivas para as organizações. 
Desta forma, infere-se que inovação pode ser considerada como a implementação de novas técnicas, idéias ou métodos de gestão, com resultados práticos como, por exemplo, a melhoria de serviços prestados e redução de custos.

Partindo da idéia de que o conhecimento pode ser uma das formas para criação de soluções inovadoras e que a TI determina o modo pelo qual a informação é armazenada, processada e distribuída, é possível dimensionar se essa tecnologia facilita o processo de "descobrir" e "criar" novas idéias para a melhoria do processo produtivo (PEREIRA; BECKER; LUNARDI, 2007).

\subsubsection{Impacto da TI sobre a Produtividade}

Segundo Perottoni et al. (2001), a partir da utilização da TI, as operações antes realizadas de forma manual, passam a ser realizadas com mais velocidade e segurança, agilizando os processos e conseqüentemente aumentando a produtividade.

A palavra produtividade trata da relação entre as entradas de recursos, trabalho e materiais e as saídas. Segundo Mukhopadhyay, Rajiv e Srinivasan (1991 apud PEREIRA; BECKER; LUNARDI, 2007 p.153) "para se detectar a existência de incrementos na produtividade de uma aplicação deve-se verificar se os benefícios proporcionados pelo investimento são superiores ao seu custo”. Dessa forma, para o aumento da produtividade organizacional, é necessário o aumento da distância existente entre o somatório do fluxo de entradas e o somatório do fluxo das saídas (PEREIRA; BECKER; LUNARDI, 2007).

Nesta pesquisa foi utilizado um instrumento destinado a mensurar a produtividade através de questões que buscam avaliar se o sistema ajuda a economizar tempo, a aumenta a produtividade e se permite que o usuário execute mais trabalho do que seria possível fazer de outra forma.

\subsubsection{Impacto da TI sobre o Controle Gerencial}

Segundo Pereira, Becker e Lunardi (2007, p.154) a TI ocupa uma importante função no processo de controle de uma empresa, através da TI é possível avaliar "coisas, pessoas e atos; além disso, pode adotar o ponto de vista comercial, técnico, 
financeiro e de segurança, aumentando a capacidade de processamento de dados necessários à geração de informações".

Segundo Pereira, Becker e Lunardi (2007) várias pesquisas foram realizadas, onde se percebe que a TI pode ser um instrumento no reforço de posições da atividade de gestão nas organizações, ou seja, ao invés de ser associada com a flexibilidade e a descentralização organizacional ela seria usada no reforço do gerenciamento centralizado e controlado.

No instrumento de pesquisa utilizado no presente trabalho, um dos fatores avalia o grupamento controle gerencial. Essas questões sugerem a avaliação do controle gerencial aplicando aos respondentes questões ou afirmações onde se busca saber se o sistema sob análise ajuda a gerência a controlar o processo de trabalho, melhora os controles gerenciais e ajuda a gerência no controle do desempenho.

\subsubsection{Impacto da TI sobre a Satisfação dos Usuários}

A mensuração da satisfação do usuário final em relação a um sistema de informação é determinante para que o investimento realizado seja revertido em ganhos para a organização, tornando possível compreender as melhorias oriundas do sistema e os resultados adquiridos pela organização. (BUBADRA; MAÇADA; RIOS, 2005).

Calisir e Calisir (2004 apud LUCHT; HOPPEN; MAÇADA, 2007, p.03), ao estudarem a influência de variáveis na satisfação dos usuários, afirmam que "os usuários finais se tornariam mais satisfeitos com os $\mathrm{SI}$ se acreditassem que a utilização do sistema aumentaria seu desempenho e sua produtividade".

Danziger e Anderosn (2002 apud LUCHT; HOPPEN; MAÇADA, 2007, p.03), afirmam que os valores associados com a satisfação dos usuários são muitas vezes modificados justamente por conta dos atributos de uma TI. Itens como satisfação com o trabalho e melhoria do bem-estar foram agregados ao modelo ora proposto.

O impacto de uma $\mathrm{TI}$, sobre da satisfação dos usuários é avaliado nesta pesquisa através de questões que buscam identificar, se o sistema possui as informações que os usuários necessitam para realizar suas atividades diárias de trabalho, se melhora a satisfação do usuário e se melhor o bem estar no trabalho. 


\subsubsection{Impacto da TI sobre o Processo Decisório}

Com a evolução do processo de gestão organizacional a análise do processo decisório vem sofrendo grandes alterações. A imprevisibilidade e complexidade do ambiente externo às empresas,é um fato perceptível no decorrer das ultimas décadas.

Dussauge e Ramanantsoa (1987 apud MARCOVITCH, 1996, p.28) afirmam que a TI pode influenciar nas decisões estratégicas de uma organização em três pontos distintos:

- A área que a organização atua, suas fronteiras, segmentação, crescimento, maturidade e valor;

- sobre a concorrência, mudando regras e propiciando o surgimento ou o desaparecimento de concorrentes;

- sobre as alternativas de estratégias genéricas: liderança em custos ou diferenciação.

Marcovitch (1996, p.28) enfatiza que,

uma TI pode alterar sensivelmente a forma de uma empresa enxergar seu negócio, e a partir daí, promover mudanças capazes de alterar a dinâmica concorrencial num setor. É interessante assinalar que a nova tecnologia pode propiciar ganhos de eficiência e redução de custos ou viabilizar novas maneiras de agregar valor ao cliente em produtos/serviços oferecidos pela empresa.

Segundo Perottoni etl al.(2001) os sistemas de informação são indispensáveis para o processo de tomada de decisão, entretanto cabe ressaltar que segundo FloresPereira, Becker e Lunardi (2007) o processo decisório é um processo complexo.

Para Laudon e Laudon (2000 apud PEREIRA; BECKER; LUNARDI, 2007) um sistema de apoio à decisão é ideal no processo de tomada de decisão, pois opera num modelo simples, pode ser desenvolvido rapidamente e pode operar com dados limitados. Segundo os autores, sistemas de informações gerenciais disponibilizam informações que podem ajudar na identificação dos problemas.

Infere-se, assim, que os estudos de impacto da TI acerca do processo de tomada de decisão enfatizam a influência do contexto socioeconômico e políticocultural na forma de construção e uso da referida tecnologia (PEREIRA; BECKER; LUNARDI, 2007). 


\subsubsection{Impacto da TI sobre a Segurança da Informação}

Para Lucht, Hoppen e Maçada (2007, p.03) "segurança da informação e medidas defensivas, deve ser encarado como uma parte do escopo organizacional de segurança efetiva como ponto-chave para um gerenciamento de processo de tomada de decisão confiável".

Segundo Birchall et.al (2004 apud LUCHT; HOPPEN; MAÇADA, 2007, p.3) adoção desta variável está na "relevância que os aspectos de segurança informacional têm assumido nas organizações com o surgimento e o desenvolvimento de novas Tls". Estes autores consideram a segurança da informação como uma vantagem competitiva, não apenas uma forma de proteger sistemas de informação contra ataques ou "invasões" externas. Deste modo, o escopo segurança da informação é composto por aspectos que incluem: "confidencialidade, integridade, disponibilidade, identificação, autenticação e não-recusa" (KOVED et al., 2001; LANDWENR, 2001; WHITMAN, 2003; EZINGEAR et. al., 2005 apud LUCHT; HOPPEN; MAÇADA, 2007, p.3)

Segundo Ezingeard et. al. (2005 apud LUCHT; HOPPEN; MAÇADA, 2007, p.3), estes fatores associam o conceito de segurança de informação à "determinação de como a confiabilidade, a segurança e a disponibilidade das vantagens de informações da companhia devem ser gerenciadas de maneira a prover o maior benefício à organização, em alinhamento com os objetivos corporativos e a estratégia".

Assim, considerando o contexto da organização em estudo e as bases teóricas descritas acima, é apresentada a seguir a metodologia utilizada na pesquisa. 


\section{METODOLOGIA}

Segundo Vergara (2000), é de fundamental importância para uma pesquisa empírica que o pesquisador informe o que pretende investigar e o porquê de tal pesquisa. Também apresentar conceitos e descrever a população, amostra e seleção dos sujeitos dentre outros aspectos relacionados ao desenho de pesquisa.

Nesta etapa, são descritos os aspectos metodológicos adotados para avaliar o impacto de um sistema de tecnologia da informação voltado para o gerenciamento de serviços de saúde na percepção dos clientes internos do Hospital Universitário de Brasília (HUB).

Vale destacar, que realização da pesquisa foi precedida de prévia autorização, o projeto de pesquisa foi aprovado pelos comitês de ética do HUB e da Faculdade de Medicina da UnB.

A seguir, são apresentados os aspectos metodológicos do presente trabalho o que inclui o tipo de pesquisa, participantes da pesquisa, instrumento, procedimentos e análise de dados.

\subsection{Tipo de Pesquisa}

Segundo Vergara (2000), é nesta etapa que se classifica a pesquisa quanto aos fins e quantos aos meios e onde será detalhado se a pesquisa será qualitativa, quantitativa ou mista.

O método de investigação utilizado na presente pesquisa é o quantitativo através do levantamento de dados (survey). No entanto, foi criado um campo ao final do instrumento de coleta de dados onde os participantes poderiam expor livremente informações que julgassem relevantes ao assunto da pesquisa. A pergunta aberta é apenas um espaço para manifestação dos sujeitos.

Segundo Fink e Kosecoff (1985, p.13 apud GÜNTHER, 1996, p. 387) a palavra survey pode ser traduzida como um "método para coletar informações de pessoas acerca das suas idéias, sentimentos, planos, crenças, bem como origens social, educacional e financeira".

Quanto aos meios, adotou-se a pesquisa, bibliográfica e de campo. A pesquisa bibliográfica para avaliar o impacto de uma TI voltada para gerenciamento de serviços de saúde na percepção dos clientes internos do HUB, foi realizada em periódicos 
científicos, impressos ou em meio eletrônico para fundamentar parte teórica e metodológica do estudo. (VERGARA, 2000).

Quanto aos fins a que se destina, a pesquisa realizada, conforme Vergara (2000), é do tipo descritiva e aplicada. Descritiva pois visa caracterizar a população a ser estudada, especialmente quanto às percepções, expectativas e sugestões. Aplicada porque é motivada pela necessidade de solucionar problemas reais, portanto, com finalidade prática (VERGARA, 2000).

Também, é uma pesquisa de campo, pois foram coletados dados na instituição onde ocorre o fenômeno investigado, conforme ressalta Vergara (2000).

\subsection{População e Amostra}

A população escolhida para o presente estudo é composta pelos colaboradores do HUB que utilizam o Sistema Gerenciador de Informações da Saúde de Individual (GSWEB). Estima-se que cerca de 350 colaboradores utilizam o sistema regularmente. Desses, foi extraído uma amostra por conveniência de 75 colaboradores, na qual constam, integrantes das carreiras de um hospital universitário, "servidores da Fundação Universidade de Brasília (FUB)" e pessoal terceirizado, "prestadores de serviço do HUB".

Essa escolha, além de atender à demanda da questão a ser pesquisada, é bastante conveniente à operacionalização da mesma devido a fatores tais como: a sua importância para a área da saúde e a facilidade de obtenção dos dados devido o fácil contato do pesquisador com a Instituição.

O melhor detalhamento da amostra dos envolvidos no processo de pesquisa será descrito a seguir no capítulo de resultados e discussão.

\subsection{Instrumento de Coleta de Dados}

Segundo Günther (1996), o levantamento de dados, deve obedecer uma estrutura básica, na qual seja, identificação do pesquisador e legitimação dos objetivos de pesquisa bem como a estrutura lógica das temáticas apresentadas na coleta de dados. 
Neste trabalho, adotou-se um questionário com perguntas fechadas, em linguagem apropriada aos participantes e estruturadas em uma escala tipo Likert, variando de 1 a 5 pontos.

Foi utilizado o questionário elaborado por Lucht, Hoppen e Maçada (2007), denominado Avaliação do Impacto da Tecnologia da Informação no Trabalho. Entre os motivos da seleção desse instrumento destaca-se que ele se adapta ao propósito da pesquisa, foi validado, e os fatores utilizados são adequados para a análise do impacto da TI em organizações hospitalares.

O Quadro 1 apresenta os fatores e os respectivos itens do questionário (Anexo A).

\begin{tabular}{|l|l|}
\hline Fatores & Itens \\
\hline Qualidade da Informação & $1,3,4,14$ e 16 \\
\hline Inovação & 5,13 e 18 \\
\hline Produtividade & 2,21 e 24 \\
\hline Controle Gerencial & 6,8 e 9 \\
\hline Satisfação do Usuário & 7,11 e 17 \\
\hline Decisão & $10,12,19$ e 22 \\
\hline Segurança da Informação & 15,20 e 23 \\
\hline
\end{tabular}

Quadro 1: Itens dos fatores no questionário.

Também foi incluído no questionário um campo onde os respondentes poderiam registrar livremente informações que entendiam como relevantes sobre o assunto. A partir da análise do conteúdo dessas informações foram identificadas categorias de respostas, a fim de caracterizar as percepções dos mesmos. Dessa forma, o instrumento buscou captar as informações necessárias, por meio de percepções, expectativas e sugestões a respeito do impacto de um sistema de informação voltado para o gerenciamento de serviços de saúde nas atividades diárias dos colaboradores do HUB. 


\subsection{Procedimentos de Coleta de Dados}

Segundo Günter (1996), o survey é aplicado por meio de questionário, às mais diversas áreas das ciências sociais, e pode ser administrado através de entrevistas, telefonemas ou em grupos. O questionário também apresenta uma série de vantagens, economiza tempo, atinge maior número de pessoas simultaneamente, obtém respostas mais rápidas e mais precisas, há maior liberdade nas respostas em razão do anonimato etc.

O processo de coleta de dados consistiu na apresentação do questionário pelo pesquisador, com as respectivas instruções de preenchimento aos respondentes.. Após a distribuição do questionário foram feitos alguns comentários sobre o objetivo do trabalho, agradecendo a colaboração do respondente. Posteriormente, o questionário foi recolhido pelo próprio pesquisador, de acordo com a disponibilidade dos respondentes. Vale destacar, que o processo de coleta de dados ocorreu durante o mês de abril de 2009.

\subsection{Análise dos Dados}

Para a análise dos dados foram utilizados os recursos disponíveis no software Statistical Package for the Social Sciences (SPSS) versão 16.0. Dentre os recursos disponíveis, utilizou-se: médias e desvios padrão que retratam os percentuais dos fatores estudados, correlações e gráficos referentes aos dados demográficos. 


\section{RESULTADOS E DISCUSSÃO}

Os resultados apresentados a seguir foram obtidos a partir da aplicação do questionário elaborado e validado por Lucht, Hoppen e Maçada (2007) denominado Avaliação do Impacto da TI no Trabalho. Esse questionário foi aplicado junto aos colaboradores que utilizam o sistema GSWEB no HUB.

Inicialmente, são apresentadas as características centrais da organização, do sistema GSWEB e por fim dos respondentes dos questionários.

Em seguida, são descritos os resultados e as discussões referentes à pesquisa quantitativa e à questão qualitativa.

\subsection{Caracterização da Instituição do Sistema GSWEB e dos Participantes da Pesquisa}

\subsubsection{Caracterização da Instituição}

O Hospital Universitário de Brasília (HUB), integrante da rede de hospitais universitários do MEC, teve o seu funcionamento autorizado pelo Decreto $n^{\circ} 70178$, de 21 de fevereiro de 1972. Inicialmente o hospital recebeu o nome de Hospital do Distrito Federal Presidente Médici (HDFPM). Mudou de nome algumas vezes até ser reconhecido pelo MEC como Hospital Universitário. Finalmente, em 1999, foi cedido à UnB, passando a se chamar Hospital Universitário de Brasília (HUB, 2009).

As atividades de ensino, pesquisa e extensão passaram a representar o grande diferencial do hospital. Assim, seu compromisso principal é formar profissionais da área de saúde atendendo as necessidades da população, produzindo conhecimento e desenvolvendo novas tecnologias, adaptadas às características e exigências de nossa sociedade (HUB, 2009).

Atualmente o hospital recebe alunos dos diferentes cursos da UnB (Medicina, Enfermagem, Odontologia, Nutrição, Farmácia, Psicologia, Serviço Social, Administração, Educação, Arquitetura, dentre outras), o HUB oferece estágios de pósgraduação e de nível médio em diferentes áreas (HUB, 2009).

O HUB contava em abril de 2009 com 289 leitos e 121 salas de ambulatório. Seu corpo clínico é formado por diversos profissionais da área de saúde. O hospital 
serve à comunidade do Distrito Federal e das cidades do entorno de Brasília, bem como outros estados, sendo, portanto um hospital de referência (HUB, 2009).

\subsubsection{Sistema Gerenciador de Informações da Saúde de Individual GSWEB}

O GSWEB é um sistema gerenciador de informações da saúde individual, que gerencia informações referentes aos usuários do sistema de saúde do qual faz parte. O sistema foi implantado no HUB em outubro de 2006 é totalmente voltado para a Internet, permitindo que os profissionais da área de saúde possam acessar o sistema e executar suas atividades de qualquer ponto do planeta, integrando os relacionamentos existentes entre agendamento de consultas, atendimentos clínicos e prescrição de receitas (vide Anexo B).

\subsubsection{Caracterização dos Participantes da Pesquisa}

Foram selecionados 75 colaboradores da instituição para responder o questionário. $\mathrm{O}$ critério para escolha dessa amostra foi o período que respondentes utilizam o sistema, o período mínimo estabelecido foi de um ano. Esse período foi estabelecido, pois se julgou que é o tempo necessário para que os respondentes possam formar opiniões coesas em relação a TI. Vale destacar, que dentre os questionários aplicados, um foi desconsiderado, pois apresentava mais de $50 \%$ dos itens não respondidos, totalizando assim uma amostra de 74 questionários respondidos.

Verificou-se, ainda, a partir dos itens de caracterização da amostra que 35 dos respondentes são do sexo feminino e 39 do sexo masculino e que a experiência média de trabalho dos respondentes na instituição era de 6 anos.

Em relação ao tipo de vínculo com a instituição verifica-se que em relação aos participantes da pesquisa $73 \%$ eram prestadores de serviços do HUB, trabalhadores estes que ingressaram na instituição sem concurso público, enquanto apenas $27 \%$ eram de servidores da FUB, trabalhadores estes que ingressaram na instituição através de concurso público.

Quanto à faixa etária, $51,4 \%$ dos respondentes possuíam até 30 anos de idade, enquanto $33,8 \%$ possuíam entre 31 e 40 anos, 9,5\% possuíam entre 41 e 50 anos e $5,4 \%$ possuíam entre 51 e 60 anos, como pode ser observado no Gráfico 1. 


\section{Faixa Etária}

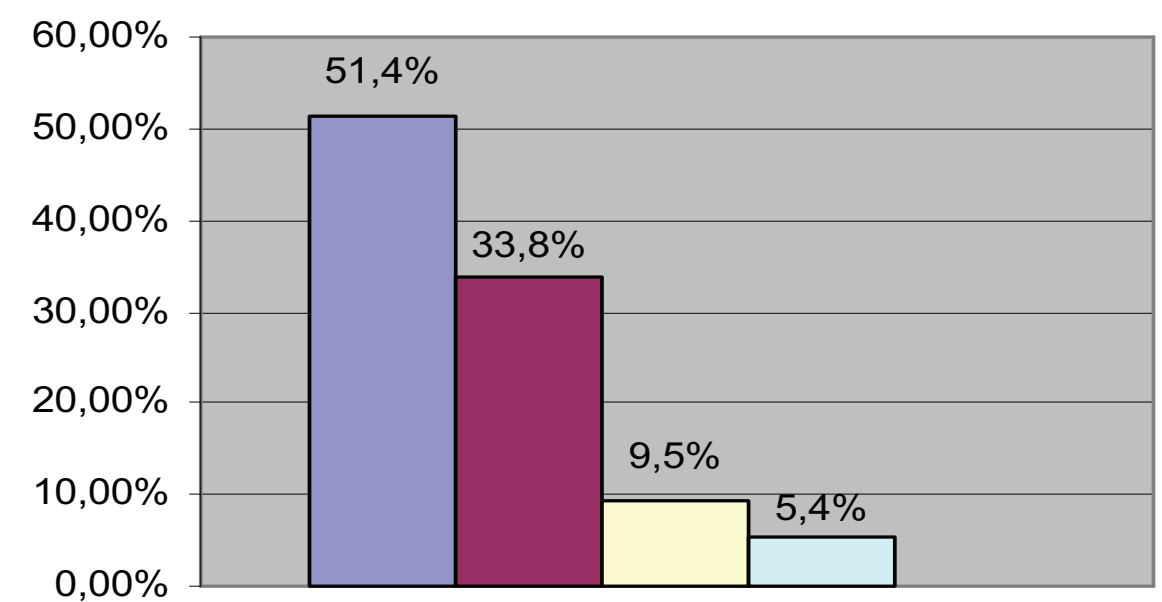

$\square$ até 30 anos

$\square$ de 31 à 40 anos

$\square$ de 41 à 50 anos

$\square$ de 51 à 60 anos

$\square$ mais de 60 anos

Gráfico 1: Faixa etária dos respondentes do questionário.

No que se refere ao nível de escolaridade, percebe-se que, $62 \%$ dos participantes da pesquisa possuindo ensino superior completo, inclusive com especialização ou mestrado, como pode ser visto no Gráfico 2.

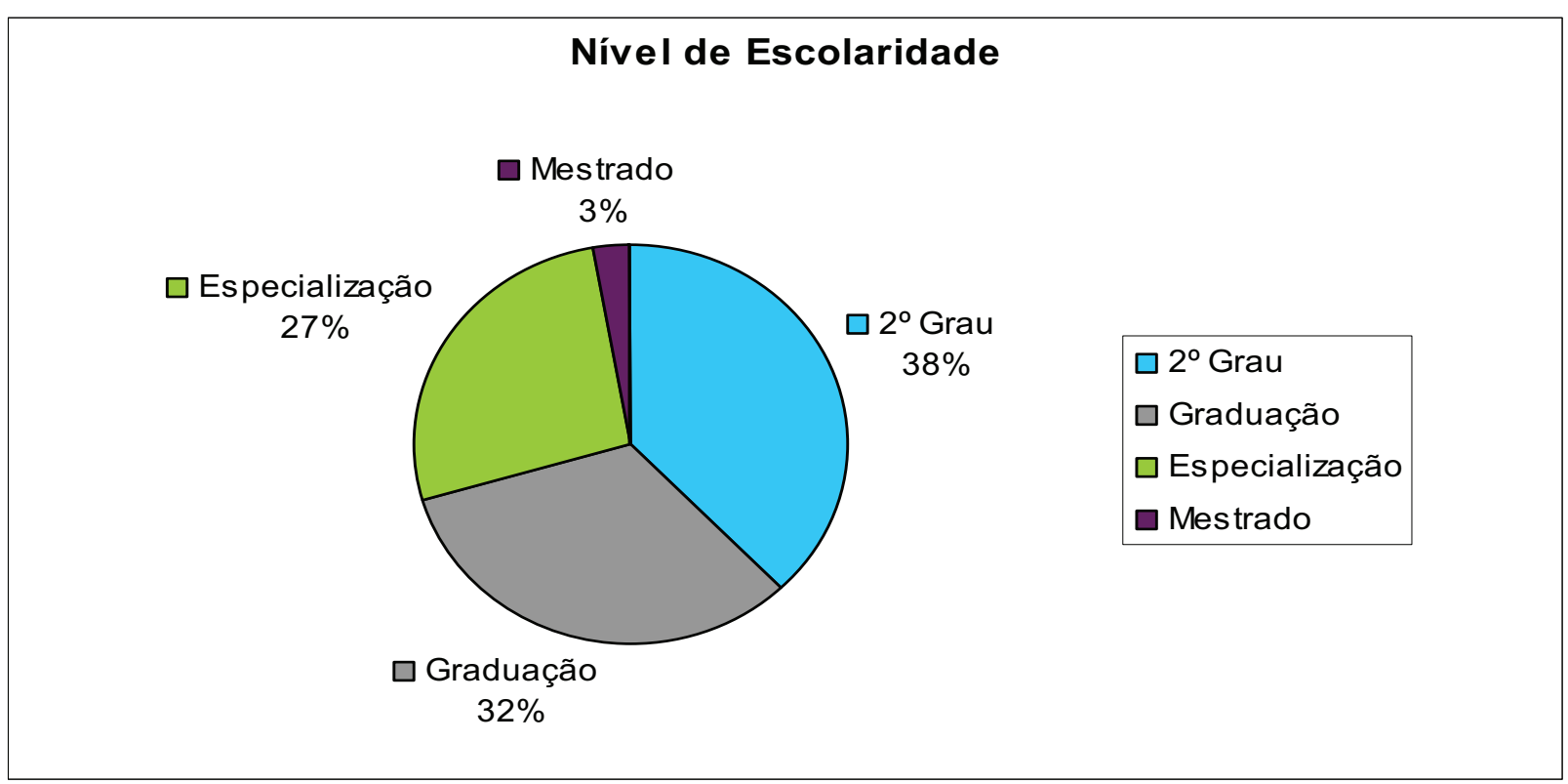

Gráfico 2: Nível de escolaridade dos respondentes do questionário.

Em relação ao cargo dos respondentes, 14,9\% eram profissionais ligados à assistência médica, enquanto $8,1 \%$ eram ligados à assistência em enfermagem; $58,1 \%$ ligados a serviços administrativos e $18,9 \%$ a outros tipos de serviços, conforme pode ser observado no Gráfico 3. 


\section{Categoria do Cargo}

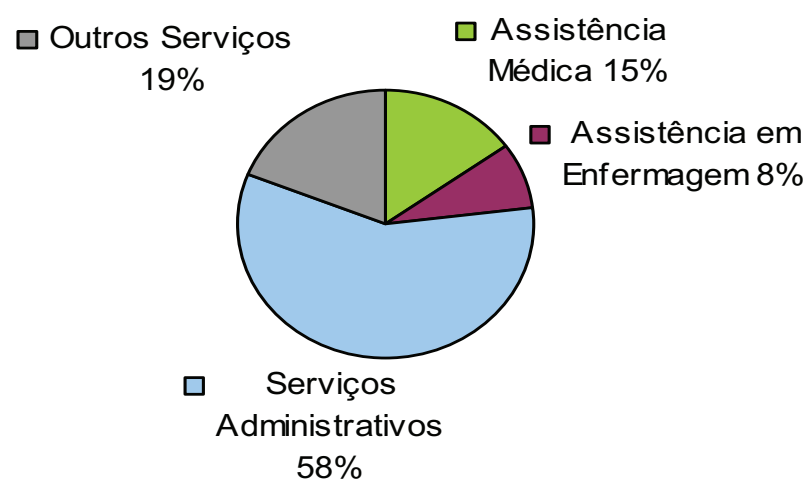

$\square$ Assistência Médica

Assistência em Enfermagem

$\square$ Serviços Administrativos

$\square$ Outros Serviços

Gráfico 3: Categoria do cargo dos respondentes do questionário.

\subsection{Resultado das médias e desvios padrão dos fatores do Modelo de Avaliação de Impacto de TI no Trabalho}

Feita a caracterização da Instituição e da amostra, são apresentadas a seguir conforme a Tabela 1 as médias e desvios padrão dos fatores 'Segurança da Informação', 'Controle Gerencial', 'Qualidade da Informação', 'Produtividade', 'Decisão', 'Satisfação do Usuário' e 'Inovação'.

Tabela 1 - Média e desvio padrão dos fatores

\begin{tabular}{l|c|c}
\hline Fatores & Média & Desvio Padrão \\
\hline Segurança da Informação & 3,48 & 0,90 \\
\hline Controle Gerencial & 3,25 & 1,00 \\
\hline Qualidade da Informação & 3,20 & 0,78 \\
\hline Produtividade & 3,18 & 1,10 \\
\hline Decisão & 3,02 & 0,94 \\
\hline Satisfação do Usuário & 2,94 & 0,99 \\
\hline Inovação & 2,68 & 1,03 \\
\hline
\end{tabular}

Do exame dos valores das médias da Tabela 1 e com base na escala utilizada no instrumento de coleta de dados da pesquisa, verifica-se, que a média das respostas situou-se entre nem pouco, nem muito e muito em relação ao fator 
'Segurança da Informação' (média: 3,48; dp: 0,90), indicando que de acordo com os respondentes o sistema apresenta muita segurança nas informações. Em relação ao fator, 'Controle Gerencial' (média: 3,25; dp: 1,00), os respondentes consideraram que o sistema aumenta nem pouco, nem muito o controle gerencial sobre as suas atividades. O fator 'Qualidade da Informação' apresentou (média: 3,20; dp: 0,78) indicando que segundo os respondentes o sistema possui nem pouca, nem muita qualidade de informação. Os respondentes também consideraram que em relação aos fatores 'Produtividade' (média: 3,18; dp: 1,10) e 'Decisão' (média: 3.02; dp: 0,94) o sistema GSWEB apresenta nem pouco, nem muito impacto em suas atividades diárias. Por fim, em relação aos fatores 'Satisfação do Usuário' (média: 2,94; dp: 0,99) e 'Inovação' (média: 2,68; dp: 1,03), os respondentes avaliaram que o sistema GSWEB apresenta entre pouco e nem pouco, nem muito impacto sobre as suas atividades diárias no trabalho.

Os desvios-padrão dos fatores ficaram relativamente próximos, à exceção daquele relacionado à 'Qualidade da Informação' (desvio-padrão de 0,78), o que demonstra uma maior unanimidade na avaliação dos respondentes em relação aos outros fatores.

Salienta-se que o fator 'produtividade', apesar da ter obtido (média de 3,18) teve o mais alto desvio-padrão, significando maior variabilidade das respostas dos sujeitos em relação à média.

A seguir, serão analisadas as médias e desvios padrão de cada item do questionário, a fim de melhor retratar as respostas.

O fator 'Segurança da Informação' busca a avaliação dos respondentes a respeito do impacto do sistema GSWEB quanto à proteção contra acessos não autorizados, segurança dos dados e controle de senhas.

Tabela 2 - Estatística descritiva dos itens que compõem o fator Segurança da Informação

\begin{tabular}{|c|c|c|c|c|c|c|c|c|}
\hline \multicolumn{2}{|r|}{ Segurança da Informação } & \multicolumn{5}{|c|}{ Número de Ocorrências } & \multirow[b]{2}{*}{ Média } & \multirow[b]{2}{*}{ DP } \\
\hline Item & Afirmação & 1 & 2 & 3 & 4 & 5 & & \\
\hline 23 & $\begin{array}{l}\text { Este sistema tem um controle de senhas } \\
\text { adequado e seguro }\end{array}$ & 4 & 7 & 12 & 32 & 19 & 3,74 & 1,11 \\
\hline 15 & $\begin{array}{l}\text { Este sistema protege os dados contra } \\
\text { acessos não autorizados }\end{array}$ & 6 & 13 & 13 & 33 & 9 & 3,35 & 1,15 \\
\hline 20 & $\begin{array}{l}\text { Este sistema aumenta a segurança dos } \\
\text { dados dos clientes. }\end{array}$ & 8 & 7 & 21 & 29 & 9 & 3,32 & 1,14 \\
\hline \multicolumn{7}{|c|}{ Média do fator Segurança da Informação } & 3,48 & 0,90 \\
\hline
\end{tabular}


Verifica-se que o item 23 que é o que mais se aproxima de muito (média: 3,74; dp: 1,11), indicando que segundo os respondentes o sistema apresenta um controle de senhas muito seguro. Quanto aos itens 15 (média: 3,35; dp: 1,15), 20 (média: 3,32; $\mathrm{dp}: 1,14)$ e 23 verifica-se, que em média, os respondentes consideram que o sistema GSWEB possui nem pouca, nem muita segurança contra acessos não autorizados e aumenta nem pouco, nem muito a segurança dos dados dos clientes. Como pode ser observado a maior quantidade de respostas do fator Segurança da Informação estão situadas no nível 4 da escala utilizada no instrumento de coleta de dados. Conforme os resultados apresentados para os itens que compõem o presente fator, evidencia-se que na percepção dos respondentes o sistema GSWEB está em conformidade com os aspectos compõem o fator 'Segurança da Informação' esses aspectos são: confidencialidade, integridade, identificação, autenticação e não-recusa, tornando a segurança da informação uma vantagem competitiva (KOVED et al., 2001; LANDWENR, 2001; WHITMAN, 2003; EZINGEAR et. al., 2005 apud LUCHT; HOPPEN; MAÇADA, 2007, p.3)

O fator 'Controle Gerencial' busca avaliar a percepção dos respondentes a respeito do suporte proporcionado pelo sistema GSWEB quanto à melhoria no controle gerencial.

Tabela 3 - Estatística descritiva dos itens que compõem o fator Controle Gerencial

\begin{tabular}{|c|c|c|c|c|c|c|c|c|}
\hline \multicolumn{2}{|r|}{ Controle Gerencial } & \multicolumn{5}{|c|}{ Número de Ocorrências } & \multirow[b]{2}{*}{ Média } & \multirow[b]{2}{*}{ DP } \\
\hline Item & Afirmação & 1 & 2 & 3 & 4 & 5 & & \\
\hline 06 & $\begin{array}{l}\text { Este sistema ajuda a Administração a } \\
\text { controlar os processos de trabalho. }\end{array}$ & 5 & 13 & 20 & 26 & 10 & 3,31 & 1,12 \\
\hline 08 & $\begin{array}{l}\text { Este sistema melhora o controle } \\
\text { gerencial das tarefas executadas. }\end{array}$ & 6 & 14 & 18 & 26 & 9 & 3,25 & 1,25 \\
\hline 09 & $\begin{array}{l}\text { Este sistema auxilia a Administração a } \\
\text { controlar o desempenho do trabalho. }\end{array}$ & 7 & 13 & 20 & 26 & 8 & 3,20 & 1,14 \\
\hline \multicolumn{7}{|c|}{ Média do fator Controle Gerencial } & 3,25 & 1,00 \\
\hline
\end{tabular}

Nota: Em um dos questionários devolvidos o item 08 estava sem marcação.

Analisando os itens 06 (média: 3,31; dp:1,12), 08 (média: 3,25; dp:1,25) e 09 (média: 3,20 ; dp:1,14) Tabela 3 , verifica-se que em média os respondentes consideram que o sistema GSWEB melhora nem pouco, nem muito a gerencia e controle dos processos de trabalho, das tarefas executadas e o controle do desempenho do trabalho, com maior quantidade de respostas situadas no nível 4 . 
A percepção apresentada pelos respondentes em relação ao impacto do sistema para o fator 'Controle Gerencial' vem ao encontro da investigação de Pereira, Becker e Lunardi (2007) na qual os autores afirmam que pesquisas indicam que a TI pode ser um instrumento no reforço de posições da atividade de gestão nas organizações, podendo ser usada no gerenciamento centralizado e controlado.

O fator 'Qualidade da Informação' visa à avaliação dos respondentes a respeito do impacto do sistema GSWEB em relação à facilidade de recuperação de informações, velocidade de recuperação de informações, a facilidade de acessos a informações, e a facilidade de compreensão e a obtenção de informações.

Tabela 4 - Estatística descritiva dos itens que compõem o fator Qualidade da Informação

\begin{tabular}{|c|c|c|c|c|c|c|c|c|}
\hline \multicolumn{2}{|r|}{ Qualidade da Informação } & \multicolumn{5}{|c|}{ Número de Ocorrências } & \multirow[b]{2}{*}{ Média } & \multirow[b]{2}{*}{ DP } \\
\hline Item & Afirmação & 1 & 2 & 3 & 4 & 5 & & \\
\hline 04 & $\begin{array}{l}\text { Neste sistema as informações geradas } \\
\text { são de fácil compreensão. }\end{array}$ & 2 & 4 & 23 & 34 & 11 & 3,65 & 0,89 \\
\hline 03 & $\begin{array}{l}\text { As informações são de fácil acesso } \\
\text { neste sistema. }\end{array}$ & 3 & 11 & 29 & 20 & 11 & 3,34 & 1,03 \\
\hline 14 & $\begin{array}{l}\text { Neste sistema as informações são fáceis } \\
\text { de se obter. }\end{array}$ & 6 & 10 & 30 & 22 & 6 & 3,16 & 1,03 \\
\hline 01 & $\begin{array}{l}\text { As informações podem ser recuperadas } \\
\text { com facilidade neste sistema. }\end{array}$ & 6 & 20 & 24 & 16 & 8 & 3,00 & 1,23 \\
\hline 16 & $\begin{array}{l}\text { Neste sistema, as informações podem } \\
\text { ser recuperadas rapidamente. }\end{array}$ & 10 & 17 & 23 & 21 & 3 & 2,86 & 1,10 \\
\hline \multicolumn{7}{|c|}{ Média do fator Qualidade da Informação } & 3,20 & 0,78 \\
\hline
\end{tabular}

Verifica-se na Tabela 4 que em relação à afirmação 04 (média: 3,65; dp: 0,89) os sujeitos consideram nem pouco, nem muito a facilidade de compreensão das informações geradas pelo sistema. A afirmação 03 (média: 3,34; dp: 1,03) obteve a avaliação dos sujeitos como sendo nem pouco, nem muito a facilidade de acesso a informações no sistema. Na afirmação 14 (média: 3,16; dp: 1,03) os respondentes avaliaram que no sistema as informações geradas são nem pouco, nem muito fáceis de se obter. Em relação à afirmação 01 (média: 3,00; dp: 1,23) as respostas dos respondentes também se situaram em nem pouco, nem muito quanto à facilidade de recuperação de informações no sistema. Já para a afirmação 16 (média: 2,86; dp: $1,10)$ os respondentes consideraram entre pouca e nem pouca, nem muita a velocidade de recuperação de informações no sistema GSWEB.

Observa-se também, que embora os sujeitos considerem que as informações são de fácil compreensão (item 4), elas não são facilmente recuperadas (item 16). 
Como citado por Oleto (2006) a qualidade da informação atribui algumas dimensões relacionadas à acessibilidade, facilidade de uso do sistema e velocidade com que os usuários obtêm as informações. Dessa forma, verifica-se que em relação ao fator Qualidade da Informação, os respondentes indicaram que o sistema GSWEB apresenta deficiências referentes à velocidade e facilidade de recuperação de informações, como pode ser observado através das médias das afirmações 01 e 16, as médias mais baixas dos itens que compõem o fator.

O fator 'Produtividade' busca a avaliação dos respondentes a respeito do desempenho do sistema GSWEB quanto à economia de tempo, melhoria de produtividade e volume de trabalho executado.

Tabela 5 - Estatística descritiva dos itens que compõem o fator Produtividade

\begin{tabular}{c|l|c|c|c|c|c|c|c}
\hline \multicolumn{1}{c|}{ Produtividade } & \multicolumn{7}{c|}{ Número de Ocorrências } & \\
\hline \multicolumn{1}{c|}{ Afirmação } & $\mathbf{1}$ & $\mathbf{2}$ & $\mathbf{3}$ & $\mathbf{4}$ & $\mathbf{5}$ & Média & DP \\
\hline 02 & $\begin{array}{l}\text { Este sistema ajuda a economizar tempo } \\
\text { na execução das minhas tarefas. }\end{array}$ & 10 & 11 & 16 & 24 & 13 & 3,26 & 1,29 \\
\hline 24 & $\begin{array}{l}\text { Este sistema melhora minha } \\
\text { produtividade. }\end{array}$ & 11 & 10 & 18 & 25 & 10 & 3,18 & 1,26 \\
\hline 21 & $\begin{array}{l}\text { Este sistema possibilita executar mais } \\
\text { tarefas do que seria possível sem ele. }\end{array}$ & 12 & 6 & 29 & 17 & 10 & 3,09 & 1,22 \\
\hline \multicolumn{7}{c}{ Média do fator Produtividade } \\
\hline
\end{tabular}

Conforme visto anteriormente segundo Perottoni et al. (2001), a partir da utilização da $\mathrm{TI}$, passam a ser realizadas com mais velocidade, agilizando os processos e conseqüentemente aumentando a produtividade. Entretanto, a partir da análise da Tabela 5 verifica-se que em relação à afirmação 02 (média: 3,26; dp: 1,29) os respondentes consideraram que o sistema ajuda nem, pouco, nem muito na economia de tempo de suas tarefas, com maior quantidade de respostas no nível 4. A afirmação 24 (média: 3,18; dp: 1,26) indica que o sistema GSWEB aumenta nem, pouco, nem muito a possibilidade dos respondentes elaborar mais trabalho do que de outra forma. Por fim, descreve-se a afirmação 21 (média: 3,09; dp: 1,22) obteve a classificação nem, pouco, nem muito quanto o aumento da produtividade dos respondentes, através do uso do sistema.

O fator 'Decisão' busca avaliar, segundo a percepção dos respondentes, o impacto do sistema GSWEB em relação ao auxilio a tomada de decisão, aos 
processos de tomada de decisão e a confiabilidade das informações do sistema para auxilio a tomada de decisão.

Tabela 6 - Estatística descritiva dos itens que compõem o fator Decisão

\begin{tabular}{c|l|c|c|c|c|c|c|c}
\hline \multicolumn{1}{c|}{ Decisão } & \multicolumn{7}{c|}{ Número de Ocorrências } & \\
\hline Itemão & $\mathbf{1}$ & $\mathbf{2}$ & $\mathbf{3}$ & $\mathbf{4}$ & $\mathbf{5}$ & Média & DP \\
\hline 22 & $\begin{array}{l}\text { Neste sistema as informaçães geradas são } \\
\text { confiáveis auxiliando na tomada de decisão. }\end{array}$ & 8 & 8 & 23 & 30 & 5 & 3,22 & 1,09 \\
\hline 10 & $\begin{array}{l}\text { Neste sistema as informações geradas } \\
\text { auxiliam os tomadores de decisão na } \\
\text { resolução de problemas. }\end{array}$ & 9 & 16 & 22 & 20 & 7 & 3,00 & 1,17 \\
\hline 12 & $\begin{array}{l}\text { Neste sistema as informações geradas } \\
\text { auxiliam na tomada de decisão. }\end{array}$ & 8 & 12 & 28 & 21 & 5 & 3,04 & 1,07 \\
\hline 19 & $\begin{array}{l}\text { Este sistema melhorou os processos de } \\
\text { tomada de decisão. }\end{array}$ & 14 & 14 & 23 & 16 & 7 & 2,84 & 1,23 \\
\hline \multicolumn{7}{c}{ Média do fator Decisão } \\
\hline
\end{tabular}

Segundo Laudon e Laudon (2000 apud PEREIRA; BECKER; LUNARDI, 2007) um sistema de apoio à decisão disponibiliza uma série de informações detalhadas que podem ajudar na resolução de problemas. Entretanto, verifica-se na Tabela 6 que em relação à afirmação 10 (média: 3,00; dp: 1,17) os respondentes consideraram que o sistema auxilia nem pouco, nem muito os tomadores de decisão na resolução de problemas. As afirmações 12 (média: 3,04; dp: 1,07) e 19 (média: 2,84; dp: 1,23) segundo avaliação dos respondentes causam nem, pouco, nem muito impacto quanto ao auxilio das informações geradas na tomada de decisão e a melhora dos processos de decisão. Já para a afirmação 22 (média: 3,22; dp: 1,09) os respondentes avaliaram que as informações geradas são muito confiáveis para o auxilio a tomada de decisão.

Embora haja confiabilidade os processos de tomada de decisão não foram aprimorados a partir da utilização do sistema. Dessa forma, verifica-se que segundo a percepção dos respondentes o sistema GSWEB não proporciona de forma eficiente todos os aspectos que compõem o processo decisório.

O fator 'Satisfação do Usuário' visa avaliar a percepção dos respondentes a respeito do nível de satisfação dos mesmos enquanto usuários do sistema GSWEB. 
Tabela 7 - Estatística descritiva dos itens que compõem o fator Satisfação do Usuário

\begin{tabular}{|c|c|c|c|c|c|c|c|c|}
\hline \multicolumn{2}{|r|}{ Satisfação do Usuário } & \multicolumn{5}{|c|}{ Número de Ocorrências } & \multirow[b]{2}{*}{ Média } & \multirow[b]{2}{*}{ DP } \\
\hline Item & Afirmação & 1 & 2 & 3 & 4 & 5 & & \\
\hline 11 & $\begin{array}{l}\text { Este sistema tem as informações de que } \\
\text { necessito. }\end{array}$ & 4 & 15 & 29 & 20 & 6 & 3,12 & 1,00 \\
\hline 07 & $\begin{array}{l}\text { Este sistema melhora minha satisfação } \\
\text { com o trabalho. }\end{array}$ & 11 & 13 & 23 & 21 & 6 & 2,97 & 1,18 \\
\hline 17 & $\begin{array}{l}\text { Este sistema melhora meu bem-estar no } \\
\text { trabalho. }\end{array}$ & 18 & 11 & 24 & 17 & 4 & 2,70 & 1,22 \\
\hline \multicolumn{7}{|c|}{ Média do fator Satisfação do Usuário } & 2,94 & 0,99 \\
\hline
\end{tabular}

Como pode ser observado na Tabela 7 , os respondentes avaliaram que em relação as afirmações 07 (média: 2,97; dp: 1,18) e 17 (média: 2,70; dp: 1,22) o sistema GSWEB melhora entre pouco e nem pouco, nem muito a satisfação e o bem-estar dos mesmos no trabalho. Em relação à afirmação 11 (média: 3,12; dp: 1,00) os respondentes avaliaram que o sistema possui nem poucas, nem muitas informações que necessitam para a execução de seus trabalhos.

$\mathrm{Da}$ análise dos itens do fator 'Produtividade' (média: 3,18; dp: 1,10) relacionados aos itens do fator 'Satisfação do Usuário' (média: 2,94; dp: 0,99) observase os valores das médias são muito próximos, supõe-se assim que os resultados obtidos estão em conformidade com a afirmação de Calisir e Calisir (2004 apud LUCHT; HOPPEN; MAÇADA, 2007) de que os usuários se tornariam mais satisfeitos com os SI se acreditassem que a utilização do sistema aumentaria seu desempenho e sua produtividade.

O fator 'Inovação' busca avaliar, segundo a opinião dos respondentes, O impacto do sistema GSWEB para que os mesmos possam ter novas idéias, encaminhar essas novas idéias e testar novas idéias em seu dia-a-dia de trabalho.

Tabela 8 - Estatística descritiva dos itens que compõem o fato Inovação

\begin{tabular}{c|l|c|c|c|c|c|c|c}
\hline \multicolumn{1}{c|}{ Inovação } & \multicolumn{7}{c|}{ Número de Ocorrências } & \\
\hline \multicolumn{1}{c|}{ Afirmação } & $\mathbf{1}$ & $\mathbf{2}$ & $\mathbf{3}$ & $\mathbf{4}$ & $\mathbf{5}$ & Média & DP \\
\hline 13 & $\begin{array}{l}\text { Este sistema me ajuda a criar novas } \\
\text { idéias. }\end{array}$ & 15 & 14 & 25 & 16 & 4 & 2,73 & 1,17 \\
\hline 05 & $\begin{array}{l}\text { Este sistema me ajuda a explorar idéias } \\
\text { inovadoras. }\end{array}$ & 17 & 12 & 23 & 17 & 4 & 2,71 & 1,21 \\
\hline 18 & $\begin{array}{l}\text { Este sistema me ajuda a testar novas } \\
\text { idéias. }\end{array}$ & 19 & 14 & 24 & 14 & 2 & 2,57 & 1,18 \\
\hline \multicolumn{7}{c}{ Média do fator Inovação } \\
\hline
\end{tabular}

Nota: Em um dos questionários devolvidos o item 05 estava sem marcação. 
Conforme se observa na Tabela 8 , os respondentes consideraram que em relação às afirmações 13 (média 2,73; dp:1,17), 05 (média: 2,71; dp: 1,21) e 18 (média: 2,57; dp: 1,18). Pode-se perceber que as respostas dos sujeitos se situaram entre pouco e nem pouco, nem muito, indicando que o software apresenta desempenho abaixo da média em relação ao fator Inovação.

A Tabela 8 demonstrou que a os itens do fator 'Inovação' apresentaram a menor média de percepção dos respondentes relacionados ao impacto da TI. Esse resultado demonstra que, sistema ajuda pouco ou nem pouco nem muito a "explorar", "testar" e "criar" novas idéias que possam ser implementadas para a melhoria do processo produtivo.

De forma a permitir conhecer a associação entre os fatores e as variáveis independentes, foi calculado o coeficiente de correlação de Pearson. Este valor varia entre -1 e +1 , determinando se a relação é negativa (relação inversa) ou positiva (relação direta).

Tabela 9 - Correlações significativas com os fatores e as variáveis independentes

\begin{tabular}{lcc}
\hline Fatores & Gênero & Tipo de Vinculo \\
\hline \multirow{2}{*}{ Qualidade da Informação } & $r=0,279\left(^{*}\right)$ & $r=0,233\left(^{*}\right)$ \\
\hline \multirow{2}{*}{ Inovação } & Sig. 0,016 & Sig. 0,046 \\
\hline \multirow{2}{*}{ Produtividade } & $r=0,232\left(^{*}\right)$ & -- \\
\hline \multirow{2}{*}{ Controle Gerencial } & Sig. 0,047 & -- \\
\hline \multirow{2}{*}{ Satisfação dos Usuários } & $r=0,242\left(^{*}\right)$ & $r=0,273\left(^{*}\right)$ \\
& Sig. 0,038 & Sig. 0,019 \\
\hline
\end{tabular}

${ }^{*}$ Correlações significativas ao nível de 0,05 .

${ }^{* *}$ Correlações significativas ao nível de 0,01 .

Na Tabela 9 são apresentados os coeficientes significativos obtidos através da correlação de Pearson entre as os setes fatores de impacto de TI pesquisados e as variáveis independentes.

Foram calculadas correlações entre os fatores e os itens de caracterização dos respondentes do questionário e apenas as variáveis independentes gênero (feminino e masculino) e tipo de vinculo (Servidores da FUB e Prestadores de Serviços do HUB) apresentaram correlações significativas. Verifica-se na Tabela 9, que os participantes do sexo feminino tendem a considerar que os fatores 'Qualidade da Informação', 
'Inovação', 'Produtividade', 'Controle Gerencial' e 'Satisfação do Usuário' causam mais impactos positivos em suas atividades diárias do que os participantes do sexo masculino.

Verifica-se também que as correlações indicam que em geral os participantes com vínculo de 'Prestadores de Serviços do HUB' tendem a considerar que fatores 'Qualidade da Informação' e 'Produtividade' causam mais impactos positivos em suas atividades diárias quando comparados aos 'Servidores da FUB'.

\subsection{Análise da Questão Qualitativa}

Ao final do instrumento de coleta de dados, foi disponibilizado um campo onde os respondentes poderiam expressar livremente qualquer informação que julgassem relevantes para a pesquisa. Entre os 74 participantes, 21 fizeram algum registro neste item.

A partir da análise do conteúdo dessas informações sugestões foram identificadas duas categorias de respostas, "elogios ao sistema" e "críticas ao sistema". Para cada categoria identificada foi transcrita a reposta dos sujeitos como forma de ilustrar tais resultados.

\section{Elogios ao sistema}

01: "Sistema considerado satisfatório".

02: "Sistema muito bom deve substituir o prontuário de papel".

03: "Tudo que é feito para melhorar a qualidade dos serviços é fundamental".

Quadro 2: Elogios ao sistema

\section{Críticas ao Sistema}

01: "Sistema muito lento! Um dia sim e o outro também o sistema para de funcionar".

02: O programa sempre dá problema nas horas mais críticas do atendimento, muitas vezes não marca o agendamento de consultas na data escolhida, freqüentemente nega acesso e fica bastante lento prejudicando o atendimento“.

03: "Sistema muito falho e lento".

04: "Infelizmente, o GSWEB não desempenha bem todas as suas funções". 
05: "O grande problema é a lentidão do programa que às vezes impossibilita a criação da prescrição eletrônica".

06: "Sistema muito falho".

07: "Sistema interessante. Porém não está funcionando, está lento e confuso".

08: "O Sistema ainda está aquém do ideal para a rotina de trabalho".

09: "O sistema geralmente dá problema em horários de pico".

10: "É importante para nossa melhoria, mas infelizmente não funciona".

11: "O sistema é muito bom, mas a parte de cadastro possui alguns campos desnecessários que poderiam ser retirados".

12: "Precisa de muitas melhorias no sistema para melhor gerenciamento".

13: "O programa referido deveria possibilitar a impressão de ordens de serviços para gerar um arquivo mais seguro".

14: "Acho que deveria ter mais treinamento para os funcionários".

15: "Na minha opinião, o sistema tem uma idéia inovadora, mas atualmente necessita de ajustes para que seus recursos sejam melhor explorados".

16: "Sugiro que seja mais abrangente o acesso ao sistema pelos colegas em todos os aspectos como busca, consulta e agilidade de respostas a serviços pedidos, para obter mais conhecimento, colocando em prática no dia-a-dia. Tendo conhecimento será proveitoso para o HUB".

17: "Deveria haver participação integral dos servidores na elaboração do sistema para facilitar a assistência aos pacientes".

18: "O sistema é bom, porém necessita de ajustes para a perfeita adequação a um hospital do porte do HUB".

Quadro 3: Críticas ao sistema

Verifica-se no Quadro 2 que raros formam os elogios ao sistema, os respondentes apenas ponderam sobre a importância e a previsão de o sistema deverá substituir métodos de transmissão de informação.

Da análise da categoria "críticas ao sistema" observa-se que a maior parte dos respondentes, descrevem que o sistema apresenta falhas referentes à velocidade e a quedas do sistema nos horários de maior fluxo de atividades, (itens 1, 2, 3, 5, 7, 9 e 11) essas queixas confirmam os resultados obtidos através da análise do fator 'Produtividade' que apresentou média situada entre nem pouco, nem muito em relação ao impacto do sistema quanto à economia de tempo, melhoria de produtividade e 
volume de trabalho executado. Entretanto, há sugestões que visam à impressão de documentos para melhor controle e segurança das informações (itens 12,13,) apesar dos fatores Segurança da Informação e Controle Gerencial terem obtido as melhores avaliações, e sugestões que visam ajustes e a maior participação dos colaboradores na elaboração do sistema (item 15, 16 e 17).

As recomendações por parte dos respondentes acerca da maior participação dos colaboradores nas etapas de elaboração do sistema estão em concordância com a visão apresentada por Stumpf e Freitas (1997), o qual enfatizam que o envolvimento do usuário na concepção um SI ocasiona várias conseqüências positivas como a possibilidade dos usuários moldarem esses sistemas de acordo com as suas prioridades e necessidades favorecendo assim maior aceitação em relação ao sistema e às mudanças provocadas por este. 


\section{CONSIDERAÇÕES FINAIS}

Neste capítulo, pretende-se mostrar os resultados mais relevantes desta monografia, ponderar a respeito do atingimento dos objetivos geral e específicos, discorrer sobre as eventuais limitações do estudo e oferecer recomendações baseadas nas conclusões da presente pesquisa.

A partir da análise dos dados verificou-se que, segundo os respondentes, o sistema GSWEB vem apresentando lacunas em diversos aspectos pesquisados, em função de suas deficiências, como em relação aos fatores inovação, satisfação do usuário e decisão.

Vários desses itens podem ser sanados caso se faça uso da participação dos colaboradores na elaboração de parâmetros de informações necessárias a suas atividades diárias, ficando evidente que o sistema poderia ser aprimorado nos aspectos referentes à inovação, satisfação do usuário, decisão e produtividade, em especial quando se ressalta que em nenhum item o sistema atingiu nível pleno de avaliação, segundo os respondentes.

Com o objetivo de avaliar os impactos da TI na percepção dos clientes internos do HUB a presente pesquisa pode evidenciar a necessidade de se fazer alguns ajustes nas políticas de $\mathrm{TI}$ do órgão estudado. Entre estes ajustes, ressalta-se que é importante continuar com os investimentos em $\mathrm{Tl}$ enfatizando-se mais os fatores Inovação, Satisfação do Usuário, Decisão, e 'Produtividade'. Dessa forma, torna-se importante salientar as sugestões apresentadas pelos respondentes na questão qualitativa que confirma a necessidade dos ajustes mencionados, podem ser alcançados através da interação permanente entre os setores que desenvolvem o sistema, e os colaboradores que o utilizam diariamente. Recomenda-se que os colaboradores sejam estimulados a sugerir medidas de melhorias no sistema como: formas de economizar tempo, rotinas que automatizem procedimentos e meios possam auxiliar no processo de tomada de decisão.

Assim, os resultados do presente estudo podem contribuir com a Administração na condução necessária das políticas de TI da Instituição.

Quanto aos objetivos específicos, o alcance dos mesmos possibilitou a criação de um conhecimento significativo acerca dos fatores afetados pela TI. A identificação das dimensões relativas ao impacto da TI no trabalho na literatura científica permitiu a compreensão de um instrumento de medida, que possibilitou a identificação de falhas 
no sistema tornando possível a recomendação de medidas especificas para minimizar os impactos negativos da inserção de novas tecnologias na organização pesquisada.

Consideram-se como limitações desta pesquisa, o fato de a coleta dos dados não ter sido realizada em todos os setores da Instituição e grande diferença em relação ao número de sujeitos por categoria de cargo, impossibilitando correlacionar adequadamente essa variável com os fatores, uma vez que grande parte dos respondentes eram da categoria serviços administrativos.

Outra limitação que merece destaque é a falta de informações referentes ao número exato de profissionais que utilizam o aplicativo na Instituição, com essa informação seria possível definir estatisticamente uma amostra probabilística de usuários do aplicativo para a coleta de dados.

Por fim, espera-se que o presente estudo sirva de auxílio aos gestores em processos de implantação de Tls em Instituições da área de saúde. E que estudos futuros possam aprofundar a investigação sobre o assunto, visando uma melhor adaptação dos números da amostra aos números populacionais, como forma de se realizar uma análise mais coesa acerca da percepção do impacto da TI sobre o trabalho dos colaboradores do Hospital Universitário de Brasília. 


\section{REFERÊNCIAS}

ALMEIDA, C. C. e VARVAKIS, G. Valor e ciência da informação: serviços de informação baseados na gestão de operações em serviço. Informação e Sociedade, João Pessoa, v. 15, n. 1, p. 1-16, jan./jun. 2005.

BRITO, M. J.; ANTONIALLI, L. M. ; SANTOS, A. C. . Tecnologia da informação e processo de gestão em uma organização cooperativa: um enfoque estratégico. RAC Revista de Administração Contemporânea, Rio de Janeiro, p. 77-95, 1997.

BORBA, V. R. Administração hospitalar: princípios básicos. São Paulo: CEDAS, 1991.

BORGES, M. A. G. A compreensão da Sociedade da Informação. Ciência da Informação. v.4, p.25-32. 2000. Disponível em http://revista.ibict.br/. Acesso em 23 de novembro de 2008.

BUBADRA, V. S.; MAÇADA, A. C. G.; RIOS, L. R . Impacto do Investimento de um SI na Satisfação do Usuário de Empresas de Varejo. In:. Congresso Anual de Tecnologia da Informação, São Paulo. v.1, p. 1-13, 2005.

FREITAS, F.; CAMPOS, M. ; CAMPOS, B. . Gestão da inovação em pequenas e médias empresas da construção civil. In: Encontro Nacional de Engenharia de Produção: 2006, Fortaleza. Anais do ENEGEP 2006.

GURGEL JÚNIOR, G.D.; VIEIRA, M. M. F. Qualidade total e administração hospitalar: Explorando disjunções conceituais. Ciência \& saúde coletiva, 2002, v. 7, n. 2, p. 325334. 2002, Disponível em http://www.scielo.br/pdf/csc/v7n2/10251.pdf. Acesso em 10 de janeiro de 2009.

GÜNTHER, H. Desenvolvimento de instrumento para levantamento de dados (survey). In: PASQUALI. L. Teoria e métodos de medida em ciências do comportamento. Brasília: UnB-INEP, cap. 15, p. 387-403, 1996.

HOSPITAL UNIVERSITÁRIO DE BRASÍLIA. Apresentação. Disponível em: http://www.hub.unb.br/Institucional/apresentacao.htm, acesso em: 19/04/2009

LAUDON, K. C. e LAUDON, J. P. Sistemas de informação. Rio de Janeiro: LTC, 1999. 
LUCHT, R. ; HOPPEN, N. ; MAÇADA, G. . Ampliação do Modelo de Impacto de TI de Torkzadeh e Doll à Luz do Processo Decisório e da Segurança da Informação. In: XXXI EnANPAD, Rio de Janeiro, v. 1. p. 1-16, 2007.

MARCOVITCH, J. Tecnologia da informação e estratégia empresarial. São Paulo: Futura, 1996.

OLIVEIRA, A.C.M. Tecnologia de Informação: competitividade e políticas públicas. RAE Revista de Administração de Empresas. São Paulo: v.36, n. 2, 1996.

OLETO, R. R. Percepção da qualidade da informação. Ciência da Informação. Brasília, v. 35, n. 1, p. 57-62, jan/abr. 2006

PEREIRA, M. T.; BECKER, J. L.; LUNARDI, G. L. . Relação Entre Processo de Trabalho e Processo Decisório Individuais: uma Análise a Partir do Impacto da Tecnologia da Informação. RAC Revista de Administração Contemporânea, v.1, p. 10-166, 2007.

PEROTTONI R. et al. Sistemas de informações: um estudo comparativo das características tradicionais às atuais. READ Revista Eletrônica de Administração. Porto Alegre: PPGA/EA/UFRGS, v.7, n. 3, 2001.

RODRIGUES, P. H. Responsabilidade dos gestores públicos de serviços de saúde. In: Fórum de debates sobre a saúde suplementar. Rio de Janeiro: ANS, 2003.

RUAS, R. L.. A atividade gerencial no século XXI e a transformação de gestores: alguns nexos pouco explorados. Read Revista Eletrônica de Administração. Porto Alegre: UFRGS/EA/PPGA. 2000.

SABBATINI, R. M. E. O Centro de Informática Hospitalar: uma proposta de estruturação e implementação. Revista Informédica, São Paulo, p. 5-8, 1993.Disponível em: http://www.informaticamedica.org.br/informed/cih.htm acesso em 02 de abril de 2009.

SCHMITZ, L. A. ; FORCELLINI, F. A. . A Estratégia Residual: Uma proposta para a Gestão da Inovação. In: 3o. CBS - Congresso Brasileiro de Sistemas, Florianópolis, 2007. 
SILVA, T. D.; SOUZA, E. R. L. C.. Tecnologia gerencial e serviços em saúde: uma aproximação mais do que necessária. RAU Revista de Administração da UNIME, Salvador: v. 1, n. 1, 2003.

STUMPF, M. k. ; FREITAS, H. M. R. A Gestão da informação em um hospital universitário: o processo de definição do Patient Core Record. RAC Revista de Administração Contemporânea, v.1, p. 71-99, 1997.

TIDD J., BESANT, J., PAVITT, K. Gestão da inovação. São Paulo: Artmed, 2008.

VERGARA, S.C. Começando a definir a metodologia. In: Projetos de Pesquisa em Administração. São Paulo : Atlas,. cap. 4, p. 46- $\overline{53,2000 .}$ 
ANEXOS 


\section{ANEXO A \\ QUESTIONÁRIO UTILIZADO NA PESQUISA}

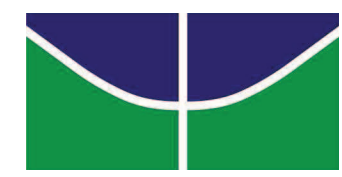

\section{Universidade de Brasília (UnB)}

Faculdade de Economia, Administração, Contabilidade e Ciência da Informação e Documentação (FACE)

Prezado (a) colega,

A presente pesquisa tem como objetivo avaliar a percepção dos clientes internos do Hospital Universitário de Brasília (HUB) em relação ao sistema de tecnologia da informação para gerenciamento de serviços de saúde GSWEB.

Cabe ressaltar que Tecnologia da informação (TI) é entendida como o complexo tecnológico que envolve computadores, hardwares, softwares, redes de comunicação eletrônica, rede digital de serviços, tecnologias de telecomunicações, protocolos de transmissão de dados e outros serviços (MARCOVITCH,1996).

Para responder às questões, deverá ser utilizada uma escala de um a cinco que tem por finalidade medir o impacto do aplicativo GSWEB sobre as suas atividades diárias de trabalho. Vale destacar que não é necessário se identificar, não existem respostas certas ou erradas e que as informações prestadas não serão utilizadas para outro fim, que não o da pesquisa.

Agradeço a sua colaboração e coloco-me à disposição para qualquer esclarecimento que se fizer necessário.

Atenciosamente,

- Jansen Roger Sousa Rodrigues Telefones: 3448-5592 / 98164098 e-mail: jansenrodrigues@unb.br 
Em relação ao impacto do sistema GSWEB nas suas atividades diárias de trabalho
utilize a escala de 1 a 5 , sendo 1 o grau mínimo e 5 o grau máximo. Por favor,
marque com um $\mathbf{X}$ apenas UMA opção de reposta para cada item.

\section{Escala a ser utilizada}

\section{1 = Pouquíssimo 2 = Pouco $3=$ Nem Pouco, Nem Muito $4=$ Muito $5=$ Muitíssimo}

\begin{tabular}{|c|c|c|c|c|c|c|}
\hline & Em que medida... & 1 & 2 & 3 & 4 & 5 \\
\hline 1. & $\begin{array}{l}\text { As informações podem ser recuperadas com facilidade } \\
\text { neste sistema. }\end{array}$ & & & & & \\
\hline 2. & $\begin{array}{l}\text { Este sistema ajuda a economizar tempo na execução } \\
\text { das minhas tarefas. }\end{array}$ & & & & & \\
\hline 3. & As informações são de fácil acesso neste sistema. & & & & & \\
\hline 4. & $\begin{array}{l}\text { Neste sistema as informações geradas são de fácil } \\
\text { compreensão. }\end{array}$ & & & & & \\
\hline 5. & Este sistema me ajuda a explorar idéias inovadoras. & & & & & \\
\hline 6. & $\begin{array}{l}\text { Este sistema ajuda a Administração a controlar os } \\
\text { processos de trabalho. }\end{array}$ & & & & & \\
\hline 7. & Este sistema melhora minha satisfação com o trabalho. & & & & & \\
\hline 8. & $\begin{array}{l}\text { Este sistema melhora o controle gerencial das tarefas } \\
\text { executadas. }\end{array}$ & & & & & \\
\hline 9. & $\begin{array}{l}\text { Este sistema auxilia a Administração a controlar o } \\
\text { desempenho do trabalho. }\end{array}$ & & & & & \\
\hline 10. & $\begin{array}{l}\text { Neste sistema as informações geradas auxiliam os } \\
\text { tomadores de decisão na resolução de problemas. }\end{array}$ & & & & & \\
\hline 11. & Este sistema tem as informações de que necessito. & & & & & \\
\hline 12. & $\begin{array}{l}\text { Neste sistema as informações geradas auxiliam na } \\
\text { tomada de decisão. }\end{array}$ & & & & & \\
\hline 13. & Este aplicativo me ajuda a criar novas idéias. & & & & & \\
\hline 14. & Neste sistema as informações são fáceis de se obter. & & & & & \\
\hline 15. & $\begin{array}{l}\text { Este sistema protege os dados contra acessos não } \\
\text { autorizados. }\end{array}$ & & & & & \\
\hline 16. & $\begin{array}{l}\text { Neste sistema, as informações podem ser recuperadas } \\
\text { rapidamente. }\end{array}$ & & & & & \\
\hline 17. & Este sistema melhora meu bem-estar no trabalho. & & & & & \\
\hline 18. & Este aplicativo me ajuda a testar novas idéias. & & & & & \\
\hline 19. & $\begin{array}{l}\text { Este sistema melhorou os processos de tomada de } \\
\text { decisão. }\end{array}$ & & & & & \\
\hline
\end{tabular}


Escala a ser utilizada

1 = Pouquíssimo $2=$ Pouco $3=$ Nem Pouco, Nem Muito $\quad 4=$ Muito $\quad 5=$ Muitíssimo

\begin{tabular}{|l|l|l|l|l|l|l|}
\hline & Em que medida... & $\mathbf{1}$ & $\mathbf{2}$ & $\mathbf{3}$ & $\mathbf{4}$ & $\mathbf{5}$ \\
\hline 20. & $\begin{array}{l}\text { Este sistema aumenta a segurança dos dados dos } \\
\text { clientes. }\end{array}$ & & & & \\
\hline 21. & $\begin{array}{l}\text { Este sistema possibilita executar mais tarefas do que } \\
\text { seria possível sem ele. }\end{array}$ & & & & \\
\hline 22. & $\begin{array}{l}\text { Neste sistema as informações geradas são confiáveis } \\
\text { auxiliando na tomada de decisão. }\end{array}$ & & & & \\
\hline 23. & $\begin{array}{l}\text { Este sistema tem um controle de senhas adequado e } \\
\text { seguro. }\end{array}$ & & & & & \\
\hline 24. & Este sistema melhora minha produtividade. & & & \\
\hline
\end{tabular}

Peço por gentileza responder alguns itens a fim de caracterizar os participantes da pesquisa.

\section{A. Gênero}

1.( ) Feminino

2.( ) Masculino

\section{B. Faixa Etária}

1.( ) até 30 anos

2.( ) de 31 à 40 anos

3.( ) de 41 à 50 anos

4.( ) de 51 à 60 anos

5.( ) mais de 60 anos

D. Tempo de serviço na instituição

\section{Nível de escolaridade}

1.( ) $1^{\circ} \mathrm{Grau}$

2.( ) $2^{\circ} \mathrm{Grau}$

3.( ) Graduação

4.( ) Especialização

5.( ) Mestrado

6.( ) Doutorado

E. Tipo de Vínculo com a instituição

1.( ) Servidor

2.( ) Prestador de Serviços HUB

F. Categoria do Cargo

1.( ) Assistência Médica

2.( ) Assistência em Enfermagem

3.( ) Serviços Administrativos

4.( ) Outros Serviços

Por favor, descrever livremente neste campo qualquer outra informação que você considere relevante sobre o assunto da pesquisa. 


\section{ANEXO B APLICATIVOS DO SISTEMA GSWEB}

\section{GS WVeb}

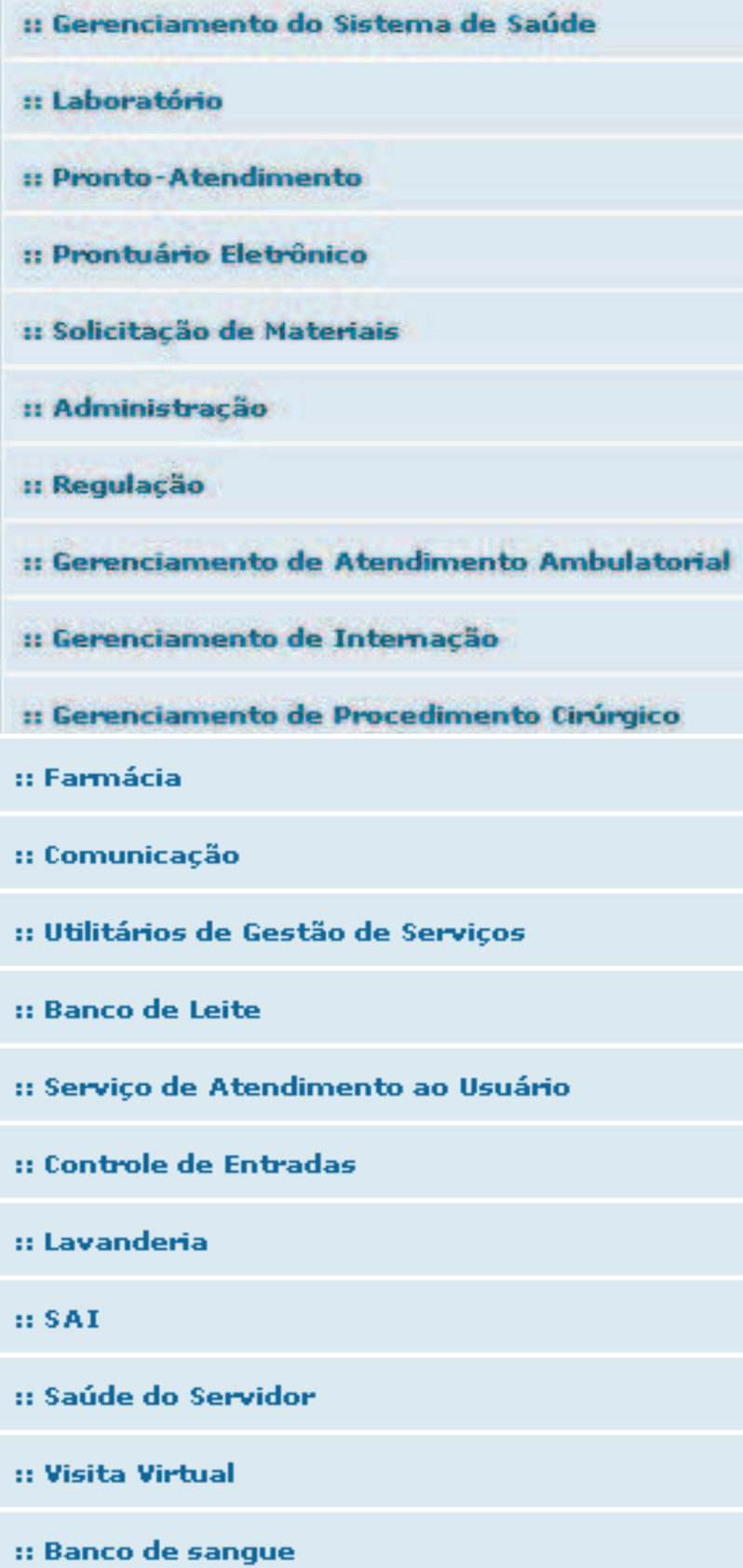


ANEXO B1

CONTROLE DE ACESSO DO SISTEMA GSWEB

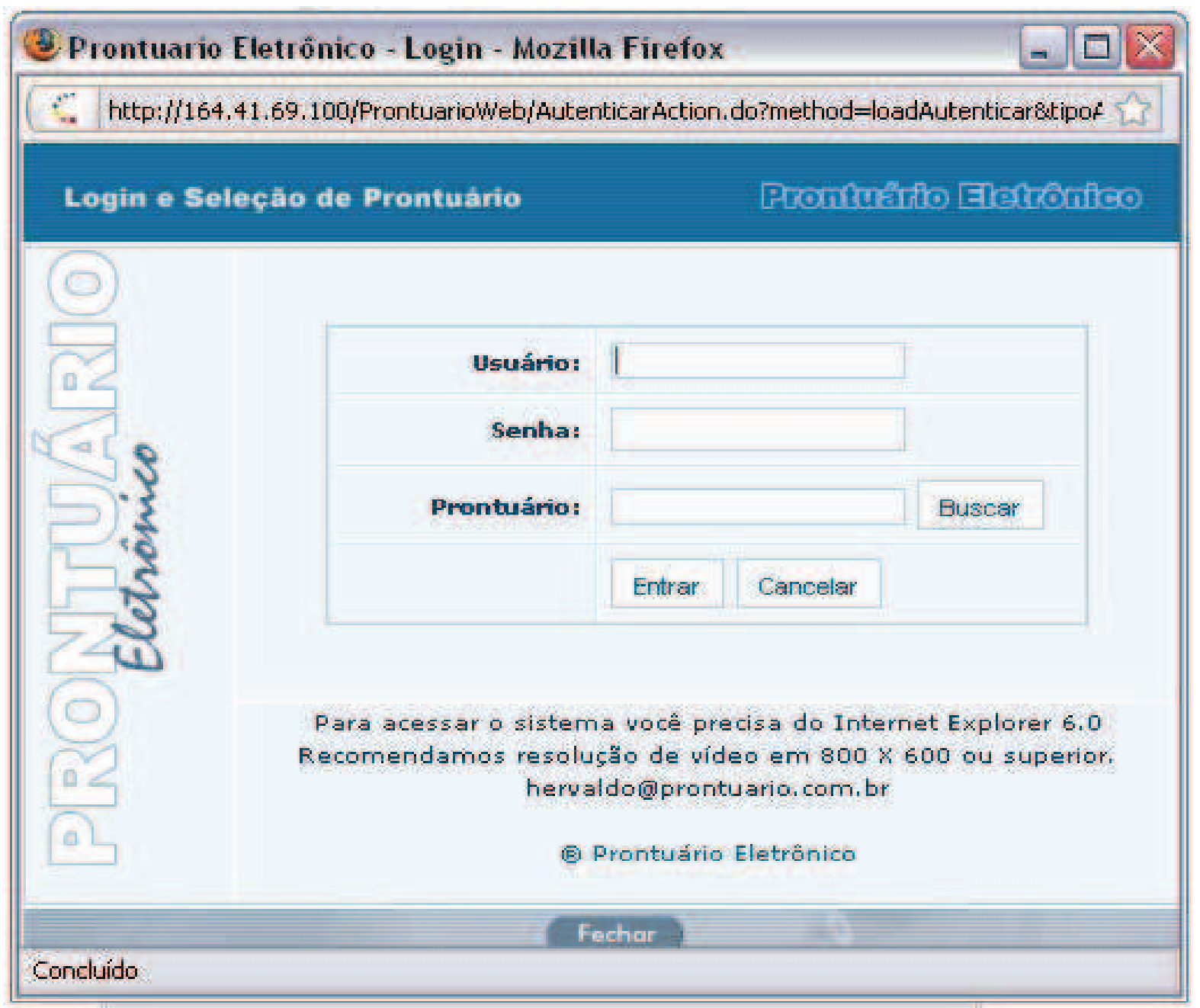




\section{ANEXO B2 \\ SISTEMA DE ATENDIMENTO TÉCNICO DO SISTEMA GSWEB}

\section{Sistema de Atendimento Técnico}

Ordem de Servigo

Monitorar os

Controle de Obj, em Manutençăo

Relatórios

Gerenciamento

$\ll<$ Menu

$<<$ Pagina Inicial

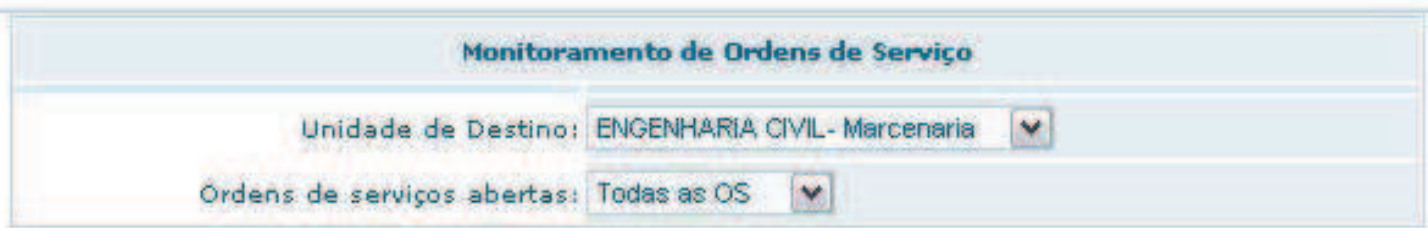

\section{Lista de OS Pendentes:}

\begin{tabular}{|c|c|c|c|c|c|c|}
\hline \multirow[b]{2}{*}{ os \#: } & \multirow[b]{2}{*}{4043} & Príoridade & Mudar prioridade & Tempo de Abertura & Data de Abertura & \multirow{2}{*}{$\square$} \\
\hline & & Imediato & Selecionar... & $\begin{array}{c}58 \text { dias, } 20 \mathrm{~h} \text { e } \\
19 \mathrm{~min}\end{array}$ & $23 / 03 / 2009$ & \\
\hline \multirow[b]{2}{*}{ os \#: } & & Prionidade & Mudar prioridade & Tempo de Abertura & Data de Abertura & \multirow{2}{*}{$\nabla$} \\
\hline & 4520 & Alta & Selecionar... & $\begin{array}{c}43 \text { dias, ooh e } \\
50 \mathrm{~min}\end{array}$ & $09 / 04 / 2009$ & \\
\hline \multicolumn{4}{|c|}{ Requerente: JANSEN ROGER SOUSA RODRIGUES } & Situacao: & Pendente & \\
\hline \multicolumn{4}{|c|}{ Ramal: 5331} & Inventário: & & \\
\hline Un & idade: & entro de Tran & ite & Sub-unidade: & \multicolumn{2}{|c|}{ Posto de enfermagem } \\
\hline
\end{tabular}

Problema: Fechadura com Defeito, Outrosi maçaneta com deifeito, cai quando abre a porta..

\begin{tabular}{|l|c|c|c|c|}
\hline & Prioridade & Mudar prioridade & Tempo de Abertura & Data de Abertura \\
\hline OS \#: 4601 & Imediato & Selecionar... & 37 dias, $21 \mathrm{~h}$ e & $14 / 04 / 2009$ \\
\hline
\end{tabular}




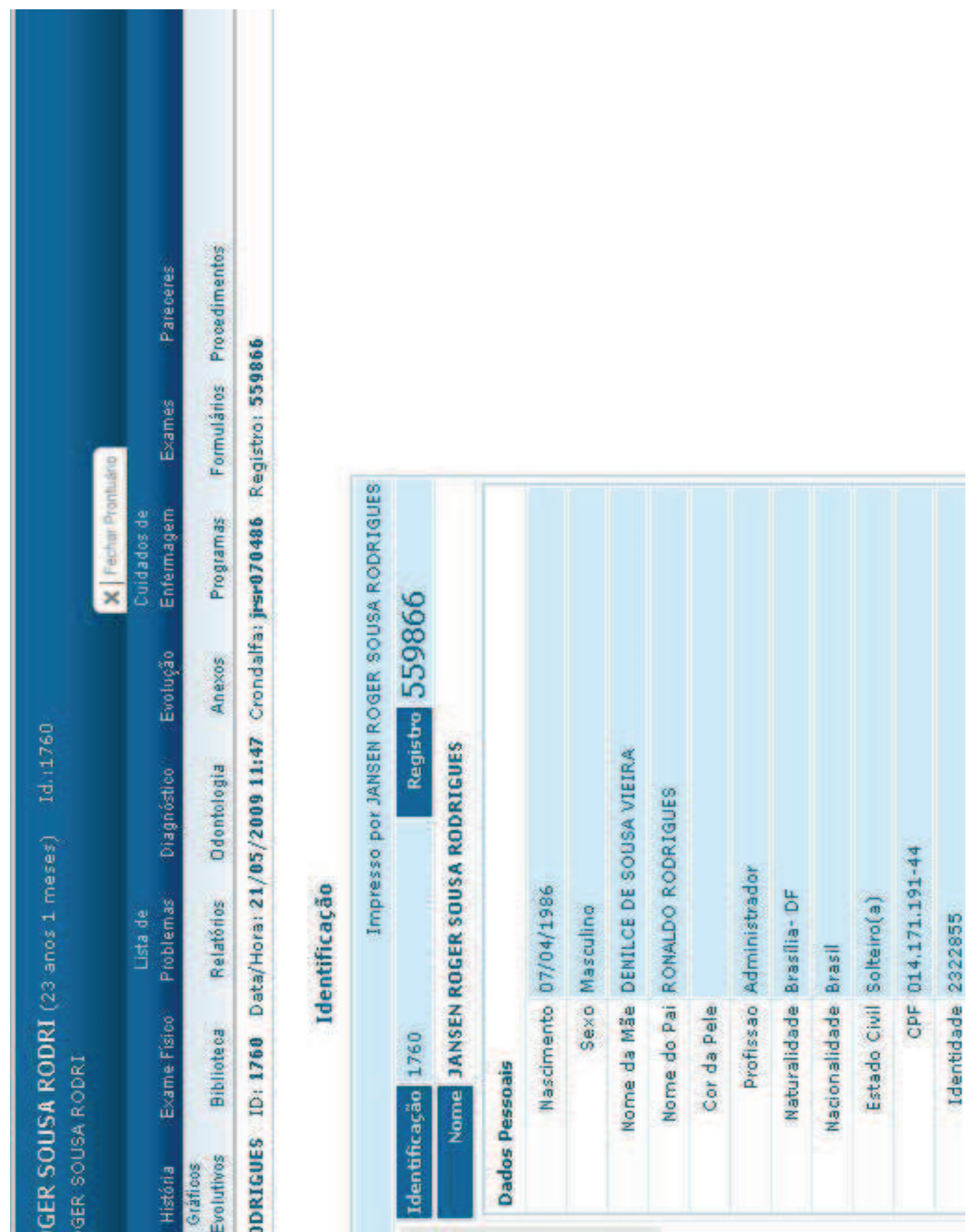

